\title{
ZONALIDADE REVERSA DOS GRANITOS DO COMPLEXO INTRUSIVO LAVRAS DO SUL, RS: PETROGRAFIA, SUSCETIBILIDADE MAGNÉTICA E ÓXIDOS DE FE-TI
}

\author{
MARIA DO CARMO GASTAL ${ }^{1}$, GUSTAVO A. FERNANDES ${ }^{2}$, FRANCISCO \\ JOSÉ F. FERREIRA ${ }^{3}$. \& RAFAEL G FRIZZO ${ }^{4}$
}

\begin{abstract}
REVERSE ZONING IN GRANITES FROM THE LAVRAS DO SUL INTRUSIVE COMPLEX, SOUTHERN BRAZIL: PETROGRAPHY, MAGNETIC SUSCEPTIBILITY AND Fe-Ti OXIDES. We evaluate the magma redox conditions of granites from the Lavras do Sul intrusive complex - LSIC (ca. 606-586 Ma). The main goal is to explain the zoning of magnetic susceptibility-k that shows a concentric pattern revealing the reverse zoning of petrographic facies. The granite pluton includes: (a) alkali-calcic, biotite granodiorite and hybrid amphibole-biotite granites in the core ( $\mathrm{k}$ of 4.0-7.5 10.3 $\mathrm{SI}$ ), and (b) alkaline, biotite-amphibole syenogranite and perthite granite that occur around the core $\left(\mathrm{k}\right.$ of $\left.9-1010^{-3} \mathrm{SI}\right)$. All facies are ferromagnetic, and the differences in $\mathrm{k}$-values are due to the distinct nature of parental magmas and to the variations in redox path shown by mafic phases (amphiboles, biotite and $\mathrm{Fe}$-Ti oxides). Divergent $\mathrm{Fe} / \mathrm{Mg}$ ratios between mafic silicates and rock imply an oxidizing environment for the crystallization of core types, in which the two Fe-Ti oxides are common (Ti-Mt:Ilm of 3:1 to 10:1). Such conditions were ascribed to the magmatic fluid phase on distinct situations, of crystal-volatile equilibrium (monzogranite) and of volatile exsolution (granodiorite). This reinforces that the core-granites represent distinct pulses of a hydrous magma $\left(3-4 \mathrm{wt} . \% \mathrm{H}_{2} \mathrm{O}\right)$ evolving at different pressure (4-2 kbar). The parental magma of alkaline granites had lower $\mathrm{H}_{2} \mathrm{O}$ content $(\sim 2 \mathrm{wt} . \%)$, and would be intrinsically oxidizing as suggested abundant Ti-magnetite (Ti-mt:ilm $\geq 20: 1$ ) and primary titanite. Convergent $\mathrm{Fe} / \mathrm{Mg}$ ratios for mafic phases and rock imply the mineralogical control in the redox path also marked by the decrease of pressure with differentiation (2-1 kbar). We conclude that the pluton formed during two major episodes of resurgence in a magma chamber related to the volcano-plutonic subsidence system-LSIC: a central event responsible for the alkali-calcic granites, and a circumferential one for the alkaline types. So, petrographic and magnetic zoning, strengthened by magnetic and gravity data, show such differences. Despite the low k-values in the core granites, a magmatic environment with varied $\mathrm{OO}_{2}$ allows the genetic link with the $\mathrm{Au}$-Cu ore occurrences.
\end{abstract}

Keywords: Magnetic petrology, Ferromagnetic granites, Magnetic susceptibility, Fe-Ti oxides, Redox conditions, Reverse zoning.

Resumo São avaliadas as condições de oxi-redução na cristalização dos granitos do complexo intrusivo Lavras do Sul - CILS (ca. 606-586 Ma), objetivando explicar o zoneamento revelado pela suscetibilidade magnética-k. Este mostra padrão concêntrico, e traduz a zonalidade reversa de fácies petrográficas, quais sejam: (a) granitos do núcleo (k de 4,0-7,5 10 $0^{-3} \mathrm{SI}$ ), álcali-cálcicos, incluindo biotita granodiorito e anfibólio-biotita granitos híbridos; e (b) biotita-anfibólio sienogranito e pertita granito (k de 910*10-3 SI), ambos alcalinos e posicionados ao redor do núcleo. Todos são granitos ferromagnéticos, e as diferenças na $\mathrm{k}$ se devem à natureza distinta dos magmas parentais e a variações na trajetória redox, registradas pelas fases máficas (anfibólios, biotita, e óxidos de Fe-Ti). Nos primeiros, os dois óxidos de Fe-Ti são comuns (Ti-mt:Ilm de 3:1 a 10:1). A divergência nas razões Fe/Mg de silicatos máficos e rocha indica cristalização em ambiente mais oxidante, devido à ação da fase fluida em situações diversas de equilíbrio cristal-volátil (granitos híbridos), ou exsolução de fluidos (granodiorito). Isto reforça que estes granitos representam pulsos distintos de magma hidratado $\left(3-4 \% \mathrm{H}_{2} \mathrm{O}\right)$, que evoluíram em diferentes pressões (4-2 kbar). Nos granitos alcalinos, a maior abundância de Ti-magnetita (Ti-mt:ilm $\geq 20: 1$ ), e a presença de titanita primária corroboram que estes derivaram de magma intrinsecamente oxidado, porém com menor conteúdo inicial de $\mathrm{H}_{2} \mathrm{O}(\sim 2 \%)$. A convergência nas razões $\mathrm{Fe} / \mathrm{Mg}$ de silicatos máficos e rocha registra o controle da mineralogia na trajetória redox, também marcada pelo decréscimo da pressão com a diferenciação (2-1 kbar). O conjunto de informações permite concluir que o pluton foi formado durante dois episódios principais de ressurgência de uma câmara magmática do sistema vulcano-plutônico de subsidência (CILS): ressurgência central para o posicionamento dos tipos do núcleo, e ao longo da perifieria do pluton para os alcalinos. Assim, a zonalidade petrográfica e magnética mostra tais diferenças, também respaldadas pelos dados magnéticos e gravimétricos. Apesar dos granitos do núcleo exibirem baixa $\mathrm{k}$, a cristalização em ambiente com grande variação de $\mathrm{fO}_{2}$ permite vinculá-los a gênese das mineralizações de Au-Cu.

Palavras-chave: Petrologia magnética, Granitos ferromagnéticos, Suscetibilidade magnética, Óxidos de Fe-Ti, Condições redox, Zonalidade reversa.

INTRODUÇÃo. O Complexo Intrusivo Lavras do Sul - CILS é uma estrutura múltipla de idade neoproterozóica $(c a$. 606-586 Ma), detalhada em Gastal et al. (2006). O pluton principal do CILS, com zonalidade reversa, equivale ao Complexo Granítico de Lavras como proposto por Nardi (1984). Esse autor reconheceu três conjuntos de fácies: granito do núcleo (granodiorito a monzogranito), transicional (monzogranito a sienogranito), e pertita granito (Fig. 1C). Os dois termos extremos exibem afinidade geoquímica contrastante, shoshonítica e alcalina, respectivamente. Fundamentado em dados litogeoquímicos, Nardi (1984) postulou que o granito transicional resultou da assimilação do granodiorito central pelo magma granítico alcalino. Tal idéia é contraditória à proposição de Vieira Jr. \& Soliani Jr. (1989), que sugeriram gênese e evolução comum para todos os granitos com base em isótopos de $\mathrm{Sr}$. O mapeamento detalhado, aliado a estudos petrográficos e de química mineral, possibilitou a re-interpretação desta intrusão. A principal modificação diz respeito ao granito transicional, que foi subdividido

1 - Centro de Estudos em Petrologia e Geoquímica, Instituto de Geociências, UFRGS, caixa postal 15 022, Porto Alegre, RS, 91 501-970, Brasil, e-mail: maria.gastal@ufrgs.br 2 - Instituto de Geociências, UFRGS, bolsista PIBIC-CNPq

3 - Laboratório de Pesquisas em Geofisica Aplicada, Departamento de Geologia, UFPR, caixa postal 19 001, Curitiba, PR, 81531-980, Brasil, e-mail: francisco.ferreira@ufpr.br Instituto de Geociências, UFRGS, bolsista IC-FAPERGS

4 - Instituto de Geociências, UFRGS, bolsista IC-FAPERGS 


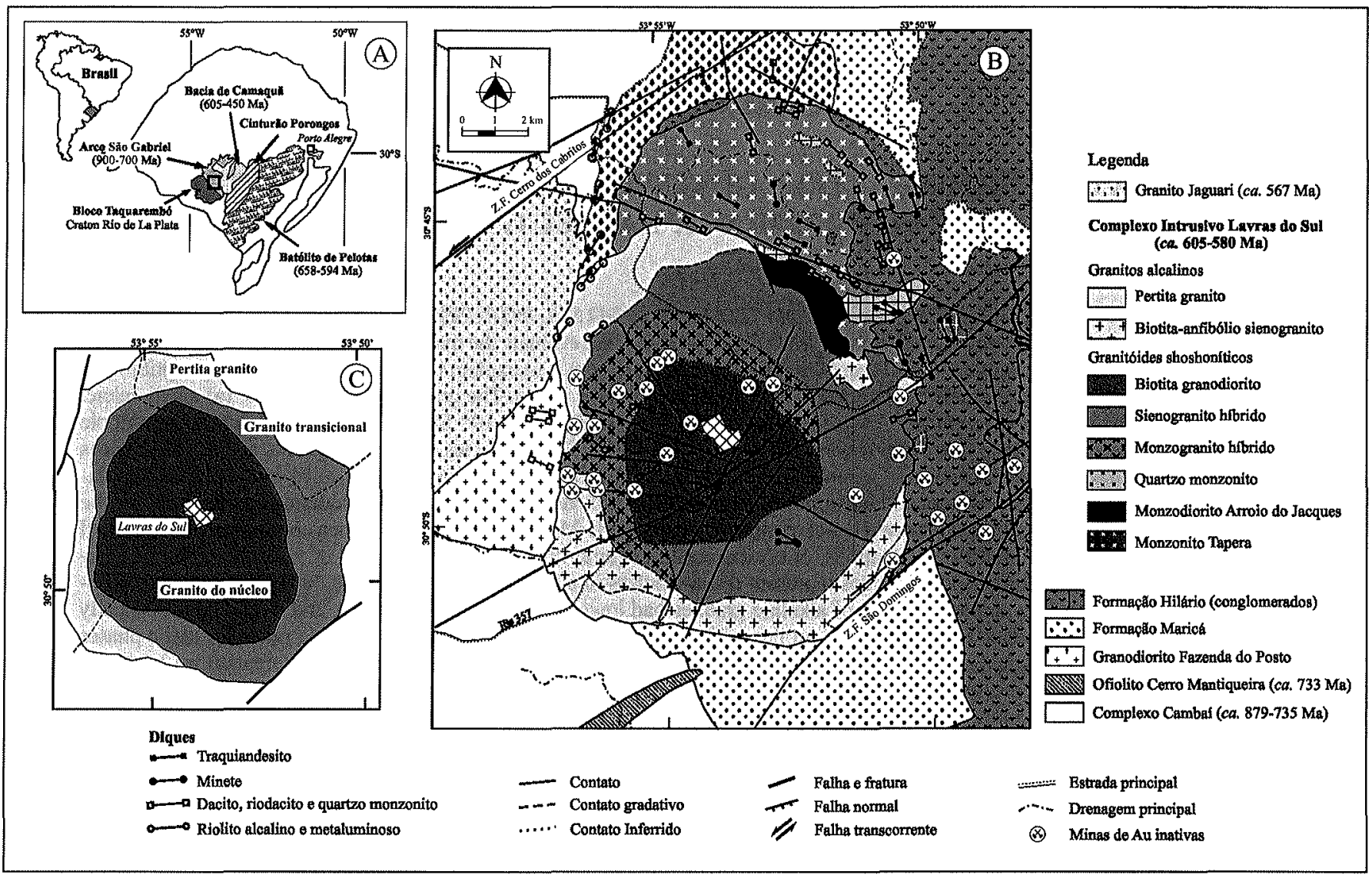

Figura 1-A - Compartimentos geotectônicos do Escudo Sul-riograndense; B - Mapa geológico do complexo intrusivo Lavras do Sul-CILS, conforme Gastal et al. (2006); C-Mapa geológico esquemático do corpo granitico do ClLS com a subdivisão de fácies petrográficas segundo Nardi (1984).

em dois tipos: granitos híbridos álcali-cálcicos e sienogranito alcalino. As ocorrências históricas de $\mathrm{Au}-\mathrm{Cu}-(\mathrm{Mo}-\mathrm{Pb}-\mathrm{Zn}-\mathrm{Ag})$, alojadas em veios de quartzo (Reischel 1980, Mexias 2000), estão preferencialmente em zonas de transição/interação de fácies neste pluton. $\mathrm{O}$ estudo detalhado dos granitos torna-se, assim, uma das questões importantes ao entendimento da gênese das mineralizações. São apresentadas a petrografia, caracterização textural e química de minerais óxidos de Fe-Ti e suscetibilidade magnética dos granitos do CILS. Estas informações são complementadas pela química de rocha (RT) e de silicatos máficos, detalhadas em Gastal \& Lafon (2006), objetivando avançar a discussão sobre a petrologia magnética e explicar as variações de suscetibilidade magnética. Isto envolveu estudos da química e textura de rocha e minerais capazes de servir como traçadores do $\mathrm{Fe}$ e, por conseqüência, das condições de oxi-redução durante a cristalização e resfriamento do pluton granítico do CILS.

GEOLOGIA DO COMPLEXO INTRUSIVO LAVRAS DO SUL - CILS. Lavras do Sul está situada no oeste do Escudo Sul-riograndense, no domínio do arco magmático São Gabriel próximo ao limite com a borda cratônica - Bloco Taquarembó (Fig. 1A). As unidades regionais incluem sequiências metavulcano-sedimentares e ultramáficas, secionadas por metagranitóides cálcio-alcalinos baixo- a médio-K, todos formados durante a orogênese São Gabriel (900-700 Ma). O CILS e as vulcânicas cronocorrelatas (Formação Hilário), como discutido em Gastal et al. (2006), representam a principal área de exposição do evento magmático pós-colisional da orogênese Dom Feliciano com idades ao redor de 606-583 Ma.

$\mathrm{O}$ complexo intrusivo possui dimensões de $12 \times 17 \mathrm{~km}$. É intrusivo em ortognaisses e granitóides do Complexo Cambaí a sudoeste e norte-noroeste, no granodiorito Fazenda do Posto a oeste, e nas formações Maricá e Hilário, respectivamente a sul e leste (Fig. 1B). A segmentação do CILS, em dois setores - norte e sul, é respaldada pelos dados aeromagnéticos (Gastal et al. 2006). No norte está o monzonito Tapera (MT), e o setor sul consiste no corpo granítico circundado parcialmente a norte-nordeste pelo monzodiorito Arroio do Jacques (MAJ). O corpo principal do CILS, com dimensões de 12 x $13 \mathrm{~km}$, é uma intrusão granítica centrada com zonalidade reversa de fácies petrográficas (Fig. 1B). As idades ${ }^{206} \mathrm{~Pb} /{ }^{238} \mathrm{U}$ e ${ }^{207} \mathrm{~Pb} /{ }^{206} \mathrm{~Pb}$ para granitóides revelam dois períodos na construção do CILS, ca. 603-597 e 586-580 Ma (Gastal et al. 2006). O primeiro (603 a $597 \mathrm{Ma}$ ) é o principal período, durante o qual foram formadas as principais unidades intrusivas. O episódio tardio (ca. 586-580 Ma) é responsável por algumas ocorrências de granitos alcalinos, e os últimos eventos hidrotermais relacionados as mineralizações de $\mathrm{Au}-\mathrm{Cu}$. Diques de composição variada secionam as unidades do CILS. Incluem rochas intermediárias no setor norte, e riolito-dacito e minetes no corpo granítico. As mineralizações de $\mathrm{Au}-\mathrm{Cu}$ estão concentradas em uma faixa de direção E-W a WNW-ESE, posicionada no centro do corpo principal do CILS, e que se estende por $5 \mathrm{~km}$ para leste no domínio da sequiência vulcânica cronocorrelata (Fig. 1B). Esta última, por sua vez, é associada às unidades precoces na construção do CILS (MT e granitos do núcleo), de afinidade shoshonítica (Lima 1995).

MATERIAIS E MÉTODOS. A suscetibilidade magnética $\mathrm{k}$ é uma propriedade física intrínseca a uma substância (mineral, rocha, etc.) e reffete o grau segundo o qual esta pode ser magne- 


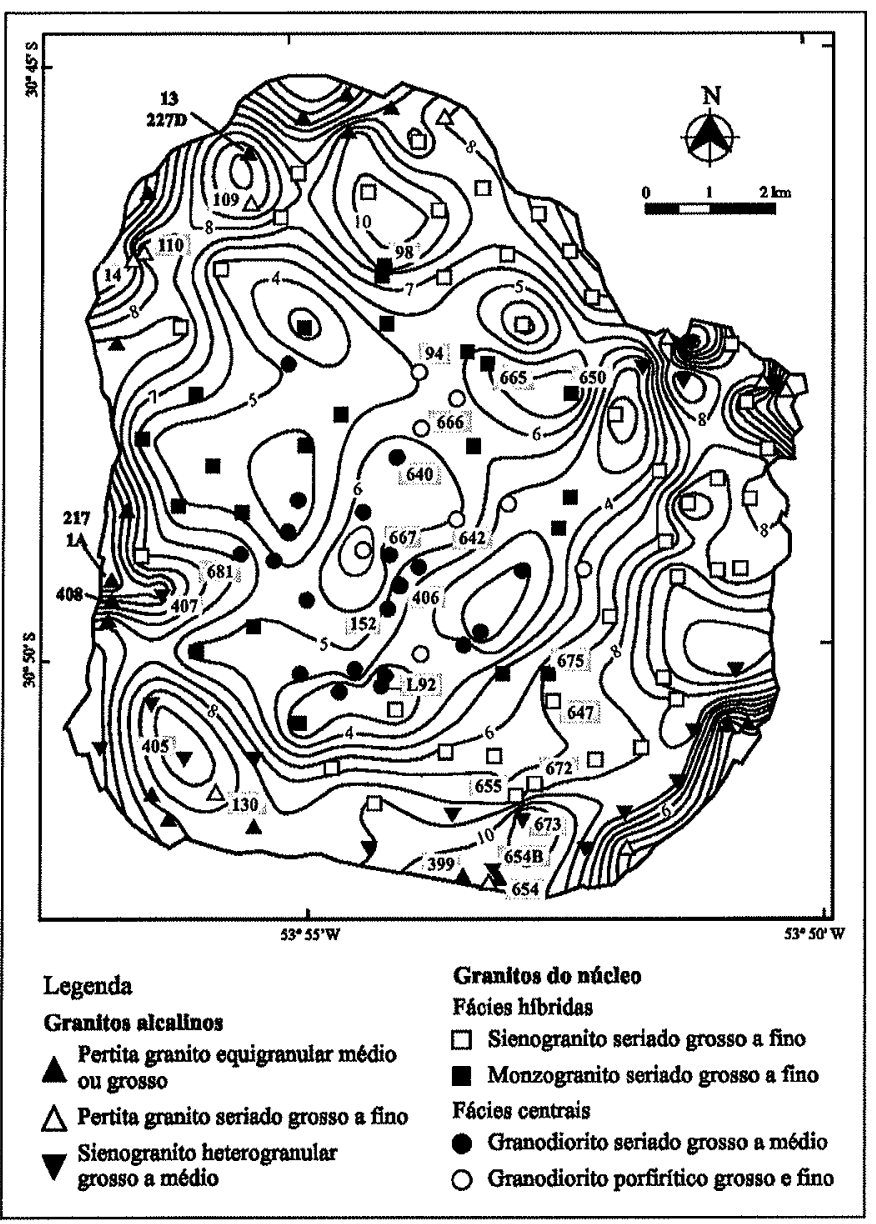

Figura 2-Mapa de contorno de susceptibilidade magnética - $k$ para os granitos do Complexo Intrusivo Lavras do Sul. Curvas a intervalos de $110^{-3} \mathrm{SI}$ traçadas com base nos valores médios por afloramento. Pontos de amostragem classificados de acordo com a petrografia, sendo identificados aqueles com análise modal (Tab. 1) e química dos óxidos de Fe-Ti (Tabs. 4 e 5).

tizada (Carmichael 1996, Clark 1997). Representa a razão entre a magnetização - $\mathrm{M}$ ou I (densidade de fluxo magnético), e a força magnetizante $-\mathrm{H}$ (campo magnético indutor), qual seja: $\mathrm{k}=\mathrm{M} / \mathrm{H}$ (sistema SI) e $\mathrm{k}^{\prime}=\mathrm{I} / \mathrm{H}$ (sistema CGS). A suscetibilidade magnética é adimensional, porém sua magnitude é distinta nos dois sistemas: $k=4 \pi k$, sendo $k$ referida em unidades SI. Para determinação de k em afloramento, utilizou-se o suscetibilímetro KT-3 (Exploranium Radiation Detection Systems), que opera com um campo magnético de baixa intensidade $(0,1 \mathrm{mT})$ e cuja resolução é de $0,0210^{-3} \mathrm{SI}$. Foram efetuadas entre 8 e 10 medidas por afloramento, obedecendo a uma malha de cerca de $1 \mathrm{~km}$ por $1 \mathrm{~km}$ (Fig. 2). Para cada afloramento, num total de 134, foram feitas as correções devidas à rugosidade da superficie da rocha, que também foi avaliada quanto à intensidade da alteração intempérica ou hidrotermal. Os dados foram tratados de forma diferenciada para cada afloramento, considerando as medidas independentes do grau e natureza da alteração, ou apenas as obtidas em rocha sã. Entretanto, os mapas de contorno de $\mathrm{k}$ construídos com os dois bancos de dados não mostraram diferenças qualitativas importantes. Os dados aeromagnéticos utilizados são do Projeto Aerogeofísico Camaquã (Jackson et al. 1973), e a interpretação e discussão detalhada dos mesmos são apresentadas por Ferreira et al. (em preparação). Análises modais de 30 amostras representativas dos granitos foram obtidas com a contagem de 3000 pontos por lâmina delgada (Tab.
1), fazendo-se a contagem em lâminas duplicadas, quando necessário, para diminuir os desvios devido a heterogeneidades texturais. A proporção Tì-magnetita:ilmenita foi avaliada de forma empírica, por contagem de grãos em campos representativos de cada lâmina, e o reconhecimento de microtexturas foi feito no microscópio eletrônico de varredura JEOL - JSM 5800 do Centro de Microscopia Eletrônica da Universidade Federal do Rio Grande do Sul - UFRGS. Análises químicas dos minerais óxidos de Fe-Ti para 9 amostras foram efetuadas na microssonda eletrônica Cameca Camebax SX-50 do Centro de Estudos em Petrologia e Geoquímica - CPGq/UFRGS. As análises foram obtidas no modo WDS (wavelength dispersive spectroscopy), utilizando os padrões sintéticos $\mathrm{MnHO}(\mathrm{Mg}$, Fe e Mn), ANOR (Al, $\mathrm{Ca}$ e $\mathrm{Si}$ ), $\mathrm{TiO}_{2}$ e $\mathrm{Cr}_{2} \mathrm{O}$. As condições de leitura foram de 15 $\mathrm{KeV}, 25 \eta \mathrm{A}$, diâmetro de feixe de $1 \mu \mathrm{m}$ e tempo de contagem de $30 \mathrm{~s}$ para o $\mathrm{Mg}$, $\mathrm{Al}$ e $\mathrm{Si}$, e de $20 \mathrm{~s}$ para os demais elementos. Nestas condições, o limite de detecção dos óxidos de elementos menores é de 0,02-0,04\% para $\mathrm{Si}, \mathrm{Mg}$ e $\mathrm{Ca}$, e de $0,04-0,08 \%$ para $\mathrm{Cr}, \mathrm{Mn}$ e $\mathrm{Al}(<0,10 \%)$. As análises foram classificadas de acordo com os tipos texturais de óxidos de Fe-Ti definidos em termos da morfologia e granulação (veja tabelas 4 e 5), o que traduz aproximadamente a natureza magmática (tipos A e B), ou subsolidus (tipo C).

\section{PLUTON GRANÍTICO}

Geologia Os granitos do CILS são todos isotrópicos. O contato entre fácies é gradativo ou brusco, mas sem afinamento da granulação, indicando pequeno contraste termal. Margem resfriada félsica é restrita ao contato externo de granitos alcalinos a oeste-noroeste. $O$ biotita granodiorito- BG central é subdividido em dois tipos texturais, seriado e porfirítico. $O$ último é composicional e texturalmente mais variado e forma bolsões na parte central, próximo à cidade de Lavras do Sul. Está associado a porções discretas de micropegmatóide ou aplito, e schlieren máficos. Os granitos híbridos ocorrem ao redor deste núcleo e exibem leve afinamento da granulação no sentido centro-borda. São dominantemente anfibólio-biotita monzogranitos, que foram subdivididos em função da razão biotita/anfibólio e da granulação do K-feldspato (Kfs). É informalmente designado de sienogranito híbrido (Figs. 1 e 2), o tipo levemente enriquecido em Kfs e de coloração mais rosada. O monzogranito híbrido (s.s.), associado à maior abundância de enclaves microgranulares, predomina no oeste e norte. Na parte leste-nordeste, próximo à seqüência vulcânica, o sienogranito híbrido varia para tipos porfiríticos e é secionado por inúmeras apófises de pertita granito, sugerindo que este predomina em subsuperfície. Nos granitos do núcleo, a transição e alternância de tipos é maior, de modo que para estes foram delimitadas áreas de dominância no mapa geológico (Fig. 1B). Os granitos alcalinos formam corpos semicirculares e pequenos stocks periféricos. São texturalmente homogêneos e exibem ocorrência polarizada: biotita-anfibólio sienogranito-BAS no sul-sudeste, e pertita granito-PG no oestenoroeste. No contato interno destes, a sudeste e noroeste-oeste, enclaves máficos e microgranulares são freqüentes. Matos Neto et al. (1980) denominaram de granitos do Bloco Butiá, intrusões menores com riebeckita situadas no contato externo do $P G$ a sudoeste. No entanto, não foram encontradas ocorrências mapeáveis de tipos peralcalinos que justifiquem tal proposição.

Petrografia $\mathrm{O}$ plagioclásio $(\mathrm{Pl})$ varia de andesina a albita, e o feldspato potássico (Kfs) é o ortoclásio com micropertitas $(<0,02 \mathrm{~mm})$ freqüentes, e pertitas $(>0,05 \mathrm{~mm})$ ocasionais. Os grãos de quartzo (Qtz) mais precoces na cristalização, no geral, estão tensionados e fraturados. No conjunto, os granitos mostram razão Kfs/Pl variada e percentual quase constante de Qtz (Tab. 1), definindo trend horizontalizado no diagrama QAP (Fig. 


\begin{tabular}{|c|c|c|c|c|c|c|c|c|c|c|c|c|c|c|c|}
\hline & & \multicolumn{7}{|c|}{ Granito híbrido } \\
\hline & \multicolumn{6}{|c|}{$\begin{array}{l}\text { Granodiorito - BG } \\
\text { Seriado }\end{array}$} & \multicolumn{2}{|c|}{ Porfirítico } & \multicolumn{4}{|c|}{ Monzogranito - ABM } & \multicolumn{3}{|c|}{ Sienogranito - ABS } \\
\hline & Kl 640 & Kl 681 & Kl 667 & KI 152 & L 92 & Kl 406a & Kl 94 & Kl 666 & Kl 98 & Kl 650 & Kl 665 & Kl 675 & Kl 655 & K1 672 & 1647 \\
\hline Quartzo & 10,43 & 24,30 & 25,47 & 27,07 & 29,20 & 18,17 & 20,83 & 24,70 & 22,37 & 21,87 & 19,77 & 21,23 & 18,43 & 20,40 & 23,33 \\
\hline Plagioclásio & 45,47 & 41,37 & 44,10 & 42,53 & 47,97 & 50,60 & 43,23 & 36,00 & 30,90 & 34,03 & 44,83 & 47,06 & 33,83 & 29,43 & 29,70 \\
\hline K-feldspato & 32,13 & 23,27 & 21,83 & 20,03 & 16,10 & 20,47 & 24,60 & 31,80 & 34,47 & 31,43 & 25,30 & 21,26 & 34,20 & 35,83 & 35,43 \\
\hline Albita tardia & 3,50 & 3,20 & 2,30 & 2,53 & 1,57 & 4,03 & 3,07 & 2,10 & 3,73 & 3,80 & 1,83 & 3,23 & 4,80 & 5,57 & 4,87 \\
\hline Anfibólio & 1,60 & 0,83 & 1,47 & 1,10 & 0,63 & 0,63 & 2,10 & 1,03 & 3,33 & 2,47 & 3,03 & 2,00 & 3,17 & 3,23 & 2,13 \\
\hline Biotita & 4,50 & 4,93 & 3,40 & 3,67 & 3,07 & 3,03 & 4,30 & 3,40 & 3,93 & 4,10 & 3,30 & 2,71 & 3,47 & 3,37 & 1,77 \\
\hline Opacos & 1,20 & 0,57 & 0,43 & 0,53 & 0,37 & 0,10 & 0,57 & 0,43 & 0,53 & 0,63 & 0,43 & 0,45 & 0,70 & 0,57 & 0,93 \\
\hline Acessórios & 0,50 & 0,20 & 0,23 & 0,17 & 0,23 & 0,13 & 0,13 & 0,20 & 0,27 & 0,60 & 0,70 & 0,19 & 0,37 & 0,43 & 0,50 \\
\hline Secundários & 0,67 & 1,33 & 0,77 & 2,37 & 0,87 & 2,83 & 1,17 & 0,33 & 0,47 & 1,07 & 0,80 & 1,87 & 1,03 & 1,17 & 1,33 \\
\hline Soma & 100,00 & 100,00 & 100,00 & 100,00 & 100,00 & 100,00 & 100,00 & 100,00 & 100,00 & 100,00 & 100,00 & 100,00 & 100,00 & 100,00 & 100,00 \\
\hline M & 7,80 & 6,53 & 5,53 & 5,47 & 4,30 & 3,90 & 7,10 & 5,07 & 8,07 & 7,80 & 7,47 & 5,35 & 7,70 & 7,60 & 5,33 \\
\hline Ti-mt:ilm & $3: 1$ & $3: 1$ & $>5: 1$ & $>5: 1$ & $>5: 1$ & n. a. & $5: 1$ & $5: 1$ & $10: 1$ & $10: 1$ & $10: 1$ & $10: 1$ & $10: 1$ & $10: 1$ & $10: 1$ \\
\hline Martita & n. 0. & n. $o$. & rara & presente & ocasional & n. $o$. & ocasional & ocasional & n. o. & presente & n. o. & comum & n. o. & n. $o$. & rara \\
\hline $\mathrm{k}\left(10^{-3} \mathrm{SI}\right)$ & 6,83 & 6,75 & 5,97 & 4,66 & 2,82 & 4,66 & 5,02 & 5,50 & 9,01 & 7,79 & 6,98 & 7,09 & 7,74 & 7,70 & 7,49 \\
\hline \multirow[t]{4}{*}{ Ordem de crist. } & \multicolumn{6}{|c|}{$\mathrm{Pl}-\mathrm{Amp}-\mathrm{Bt} / \mathrm{Qtz}-\mathrm{Kfs}$} & $\begin{array}{r}\mathrm{Pl} \text {-Amp - } \\
\mathrm{K} \\
\end{array}$ & $\begin{array}{l}\text { Qtz/Bt - } \\
\mathrm{fs}\end{array}$ & \multicolumn{4}{|c|}{$\mathrm{P} / \mathrm{Amp}$ - Bt/Kfs - Qtz } & \multicolumn{3}{|c|}{$\mathrm{P} 1 / \mathrm{Amp}-\mathrm{Kfs}-\mathrm{B} t / \mathrm{Qtz}$} \\
\hline & \multirow{2}{*}{\multicolumn{4}{|c|}{ Sienogranito alcalino - BAS }} & \multirow{2}{*}{\multicolumn{11}{|c|}{ Pertita granito - PG }} \\
\hline & & & & & \multirow{2}{*}{\multicolumn{4}{|c|}{$\frac{\text { Seriado }}{130}$}} & & & & & & & \\
\hline & KI 673 & Kl 407 & Kl 405 & Kl 654B & & & & & Kl 408 & Kl399* & Kl 13 & 227D & $\mathbf{A A}$ & $217 \mathrm{~A}$ & K1654 \\
\hline Quartzo & 25,03 & 24,70 & 21,03 & 17,77 & 17,30 & 18,87 & 27,45 & 29,47 & 21,34 & 24,05 & 24,62 & 32,40 & 19,12 & 29,13 & 30,23 \\
\hline lagioclásio & 12,17 & 19,43 & 17,26 & 17,67 & 3,81 & 14,55 & 1,21 & 2,66 & 2,85 & 0,46 & 1,72 & 0,00 & 6,74 & 0,60 & 0,20 \\
\hline -feldspato & 43,60 & 37,97 & 46,77 & 47,47 & 56,25 & 46,76 & 57,55 & 57,43 & 56,05 & 65,11 & 57,06 & 56,97 & 60,90 & 57,96 & 63,43 \\
\hline Albita tardia & 11,43 & 10,23 & 9,10 & 10,43 & 13,27 & 15,76 & 10,34 & 8,98 & 11,60 & 3,70 & 6,97 & 5,42 & 8,56 & 8,81 & 4,37 \\
\hline Anfibólio & 3,57 & 2,67 & 4,06 & 1,57 & 6,05 & 1,91 & 1,25 & 0,40 & 5,11 & 3,49 & 2,29 & 2,41 & 1,21 & 2,00 & 0,93 \\
\hline Biotita & 1,57 & 1,90 & 1,03 & 1,57 & 1,71 & 1,10 & 0,80 & 0,65 & 0,10 & 0,39 & 0,76 & TR & 0,60 & TR & 0,33 \\
\hline Opacos & 0,83 & 0,70 & 0,32 & 1,07 & 0,84 & 0,40 & 0,75 & 0,45 & 0,88 & 0,92 & 1,72 & 1,50 & 1,21 & 0,90 & 0,27 \\
\hline Acessórios & 0,93 & 1,13 & 0,23 & 1,10 & 0,62 & 0,55 & 0,45 & 0,00 & 0,10 & 0,10 & 0,10 & 0,80 & 1,16 & 0,40 & 0,03 \\
\hline Secundários & 0,87 & 1,27 & 0,19 & 1,37 & 0,16 & 0,10 & 0,20 & 0,20 & 1,97 & 1,66 & 4,77 & 0,50 & 0,50 & 0,20 & 0,20 \\
\hline Soma & 100,00 & 100,00 & 100,00 & 100,00 & 100,00 & 100,00 & 100,00 & 100,25 & 100,00 & 99,88 & 100,00 & 100,00 & 100,00 & 100,00 & 100,00 \\
\hline M & 6,57 & 6,40 & 5,65 & 5,30 & 9,22 & 3,96 & 3,26 & 1,41 & 6,19 & 5,02 & 4,87 & 4,71 & 4,18 & 3,30 & 1,57 \\
\hline Ii-mt:ilm & $>20: 1$ & $>20: 1$ & $20: 1$ & $>20: 1$ & $15: 1$ & n. a. & $>20: 1$ & $>20: 1$ & n. a. & $7: 1$ & n. a. & n. a. & n. a. & n. a. & $20: 1$ \\
\hline Martita & n. $o$ & n. $o$. & rara & rara & n. o. & n. 0. & ocasional & presente & n.a. & presente & n. a. & п. 0. & n. $o$ & n. $o$. & n. 0. \\
\hline$\left(10^{-3} \mathrm{SI}\right)$ & 11,50 & 11,07 & 11,68 & 10,47 & 10,43 & 9,84 & 8,12 & 12,41 & 12,39 & 10,89 & 10,93 & 10,93 & 12,39 & 12,39 & 12,45 \\
\hline rdem de crist. & & - Kfs/Amp & $-\mathrm{Qtz}-\mathrm{Bt}$ & & & $\mathrm{P} / \mathrm{Kfs} / \mathrm{Qtz}$ & - Amp - Bt & & & & $(\mathrm{Pl})-\mathrm{K}$ & $\mathrm{Kfs}-\mathrm{Qtz} / \mathrm{Ar}_{\mathrm{I}}$ & $\mathrm{mp}-\mathrm{Bt}$ & & \\
\hline
\end{tabular}

Notas: $\mathrm{M}$ - soma dos minerais máficos e acessórios; ${ }^{*}$ análises modais duplicadas; n. a. - não avaliada; n. o. - não observada; $\mathrm{TR}$ - traços; $\mathrm{k}$ - susceptibilidade magnética - valores médios em rocha sã;; secundários: clorita carbonato, $e$ menores percentuais de mica branca, pistacita e actinolita; analise modal com base em 3000 pontos/lämina. 


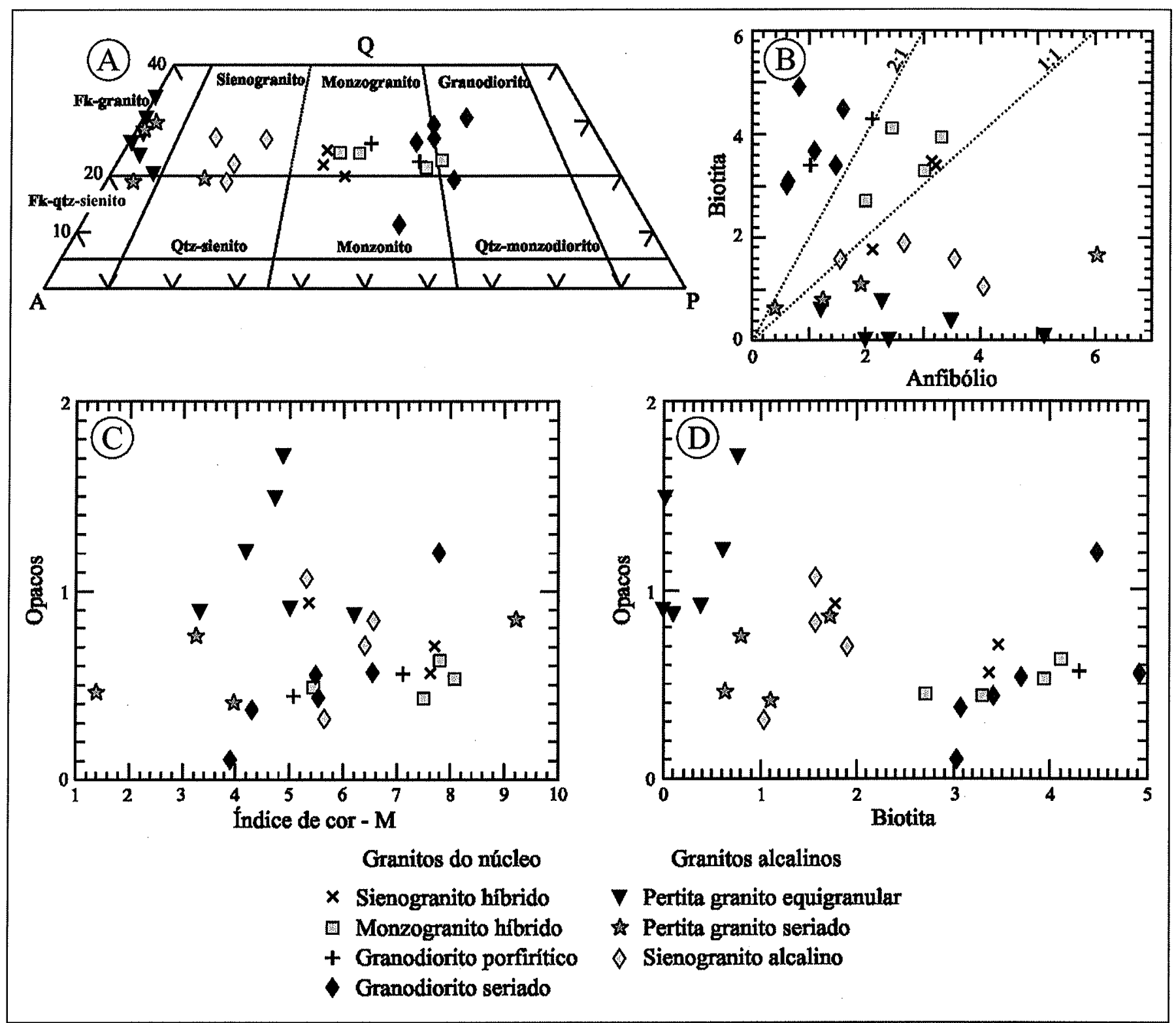

Figura 3 - Moda de granitos do complexo intrusivo Lavras do Sul-CILS. A-Seção do diagrama QAP, com a separação dos campos segundo Le Maitre (1989); e diagramas de correlação: B-Biotita vs. anfibólio, justificando a subdivisão de fácies adotada; $C$ - Opacos (Ti-magnetita e ilmenita) vs. índice de cor (M-somatório de minerais máficos e acessórios); e D-Opacos vs. biotita.

3A), dificil de ser interpretado em termos do fracionamento de um mesmo magma. As fases máficas (1- $9 \%$ ) incluem Fe-hornblenda ou Fe-barroisita, e Fe-biotita (Fig. 3B). Entre os acessórios, Ti-magnetita, zircão e titanita são freqüentes, e ilmenita, apatita, alanita e fluorita subordinados.

GRANITOS DO NÚCLEO Variam de monzogranito a granodiorito, contendo oligoclásio cálcico e percentuais de Fe-biotita $(2-5 \%)$ iguais ou superiores aos da Fe-hornblenda (1-4\%). O biotita granodiorito - BG possui PI mais cálcico (An 20-35\%) e composição variada, e o anfibólio-biotita monzogranito-ABM, em sua maioria, maiores percentuais de máficos $(\sim 7 \%)$. Além disso, a razão biotita/anfibólio decresce do BG para o ABM (Fig. 3B, Tab. 1). Ambos exibem textura seriada fina a grossa, com maiores variações texturais no $B G$ que é subdividido em dois tipos: seriado que é dominante, e porfirítico. Nesses granitos (BG e ABM), plagioclásio e anfibólio são as fases liquidi, e maiores trocas são observadas na cristalização dos demais minerais (Tab. 1). No $\mathrm{BG}$, o Kfs é o último a cristalizar e a biotita é posterior ao anfibólio e anterior ao Qtz, enquanto no ABM, a biotita é mais tardia na cristalização, sendo concomitante ou posterior ao Kfs e anterior ao Qtz. Ti-magnetita e alanita são freqüentes, enquanto ilmenita e titanita exibem comportamentos contrários. No $\mathrm{BG}$, a ilmenita é comum e precoce na cristalização, e a titanita é escassa e subsolidus. A ilmenita é escassa no ABM, enquanto a titanita intergranular torna-se mais abundante.

As texturas de desequilíbrio do plagioclásio são marcantes nestes granitos. A zonação oscilatória de grãos médios e finos de $\mathrm{Pl}$, com ou sem núcleos corroídos (patchy), é característico do BG e menos importante no ABM. Por outro lado, feições de corrosão/dissolução do $\mathrm{Pl}$ caracterizam o $\mathrm{ABM}$, e são ocasionais no BG. Estas são diversificadas e podem ser reunidas em dois conjuntos: (a) fragmentos de grãos ou de agregados compactos de grãos de $\mathrm{Pl}$, arredondados e com embaiamentos marcantes, envoltos e invadidos por Kfs e eventualmente Qtz. Os grãos de Pl são anédricos, sem zonação, estão intensamente alterados para sericita (pistacita e carbonato), e quando em agregados, são freqüentes contatos poligonizados sugestivos de recristalização; 
e (b) grãos precoces de $\mathrm{Pl}$ re-equilibrados e envoltos por Pl mais sódico, ou invadidos e corroídos por $\mathrm{Kfs}$, com a formação de textura rapakivi. Os grãos de $\mathrm{Pl}$ são limpos, com ou sem núcleos patchy, e formam agregados ocasionais com synneusis. Textura de poiquilomosaíco do $\mathrm{Kfs}$ e Qtz, indicativas de hibridismo (Vernon 1990), ocorrem no ABM. Nestes, além dos enclaves descritos por Nardi \& Lima (2000), ocorrem xenólitos arredondados de lápili-tufo (Gastal et al. 2006), e de dioritos com textura cumulada. Modificações na mineralogia e texturas permitem separar dois tipos de granitos híbridos, anteriormente referidos. $\mathrm{O}$ anfibólio-biotita sienogranito - ABS sobressai pela escassez de feições de dissolução/corrosão, e natureza mais precoce na cristalização do $\mathrm{Kfs}$ relativo à biotita. Isto resulta no maior crescimento do Kfs, enquanto o Pl predomina na fração fina, conferindo aspecto distinto em amostra de mão.

GRANITOS ALCALINOS Incluem biotita-anfibólio sienogranito - BAS e pertita granito - PG (Fig. 3A), contendo oligoclásio a albita cálcica, abundante albita tardia $(\sim 10 \%)$, escassa Fe-biotita $(<2 \%$ ), e quantidades variadas de Fe-hornblenda (Fig. 3B, Tab. 1). Em ambos (PG e BAS), o Pl e Kfs são as fases liquidi, e a biotita é tardi-magmática ou subsolidus. No BAS, o anfibólio é posterior ao Kfs e anterior ao Qtz na cristalização, enquanto no PG o Qtz é anterior ao anfibólio. A reabsorção do Pl pelo $\mathrm{Kfs}$, típica de líquidos graníticos pobres em $\mathrm{CaO}$ e subsaturados em $\mathrm{H}_{2} \mathrm{O}$ (Nekvasil 1990), cresce em importância do BAS para o PG. Nos tipos mais evoluídos do último, restos de grãos de $\mathrm{Pl}$ envoltos e reabsorvidos pelo Kfs são escassos, registrando a passagem de condições subsolvus para hipersolvus. Titanita rica em ETR-Nb-Y e Ti-magnetita são as principais fases acessórias no BAS, e a fluorita cresce em abundância com a diferenciação. No PG, a titanita é escassa, ocorrendo em porções com pouca ou sem fluorita. A ilmenita é rara no BAS e ocorre apenas em autólitos, torna-se mais comum no final da cristalização do PG mais evoluído, estando associada a concentrações de grãos tardios de albita, Kfs e Fe-barroisita.

O BAS exibe textura seriada grossa a média, com bimodalidade saliente na granulação sugerindo dois momentos na cristalização. Grãos grossos, dominantemente de Kfs (Pl e Qtz), formam o arcabouço da rocha. Estes ocorrem em agregados e estão arredondados, indicando corrosão. A fração média a fina, intergranular e de abundância variada, é composta por Kfs, Qtz, máficos e abundante $\mathrm{Pl}$, que exibe amplo intervalo composicional (An 5-32\%). Os poiquilomosaícos de Kfs, Qtz e também de $\mathrm{Pl}$ sódico são ocasionais, e as invasões de $\mathrm{Kfs}$ no $\mathrm{Pl}$, com formação de rapakivis, são raras. O PG dominante é equigranular médio ou grosso. São característicos dessa fácies, os agregados de grãos de Kfs que constituem domínios com textura adcumula$\mathrm{da}$, e de Qtz com formas globulares e embaiamentos marcantes. Neste, a biotita/anita subsolidus exibe tonalidades de amarelo ouro intenso, e a Fe-hornblenda transiciona para Fe-barroisita. Isto é relevante em amostras situadas na borda externa das ocorrências de PG. Ocorrem também variações localizadas para tipo seriado médio, grosso e fino, em que os agregados de Kfs e Qtz são pouco desenvolvidos, o PI (An 5-15\%) é comum na fração fina, e a albita tardia é mais abundante. Neste, predomina a Fehornblenda, a Fe-biotita é comum, e a titanita é ocasional. Esta variedade ocorre na borda interna das ocorrências do PG, em especial, naquela situada no noroeste do corpo granítico do CILS. Os tipos menos evoluídos de granitos alcalinos (BAS e PG seriado) estão comumente associados a concentrações de enclaves microgranulares e máficos. São também freqüentes enclaves félsicos no PG, e autólitos nos dois granitos alcalinos.

Geoquímica Os granitos do CILS são dominantemente metaluminosos. Os termos do núcleo são álcali-cálcicos, e o PG

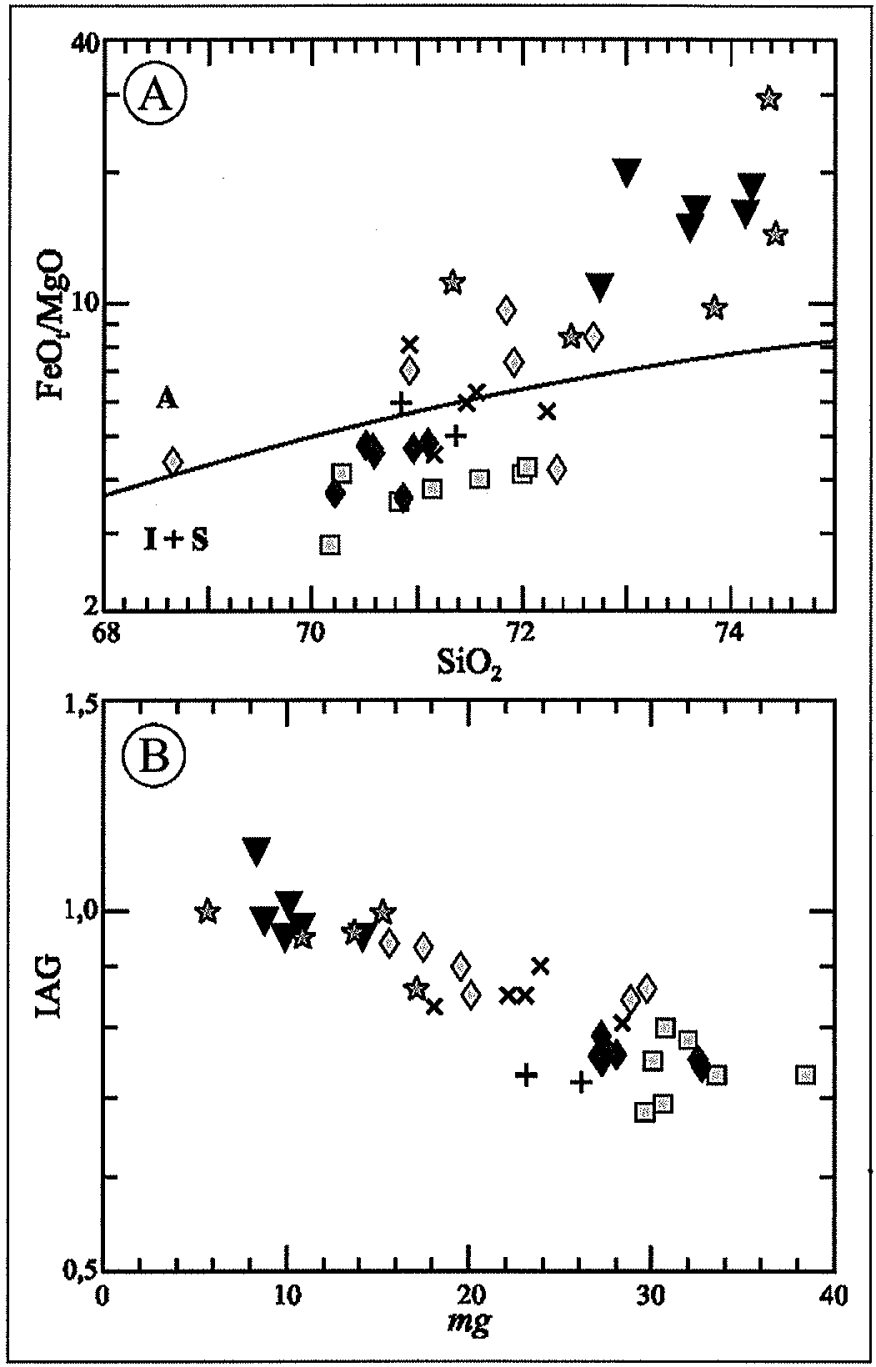

Figura 4 - Composição química (RT) de granitos do complexo intrusivo Lavras do Sul - CILS (Nardi 1984, Gastal 1998): A - Diagrama FeO/MgO vs. $\mathrm{SiO}_{2}$ (\% peso), com a separação entre os granitos $I+S$ e A, segundo Eby (1990); B - Diagrama de correlação do índice agpaítico $-\mathrm{IAG}\left(=\left(\mathrm{Na}, \mathrm{O}+\mathrm{K}_{2} \mathrm{O}\right) / \mathrm{Al} \mathrm{O}_{2}, \%\right.$ mol.) vs. número de magnésio $-m g(=\mathrm{MgO} /(\mathrm{MgO}+\mathrm{FeO}) * 100$, $\%$ mol.). Símbolos como na figura 3.

evoluiu até composições fracamente peralcalinas. A discussão mais abrangente da geoquímica destas rochas é apresentada em Gastal \& Lafon (2006). A proximidade no grau de diferenciação dos granitos (núcleo e alcalinos) confere, muitas vezes, a falsa impressão de comagmaticidade dependendo do índice utilizado para correlação. Pequeno contraste é visto no diagrama $\mathrm{FeO} /$ $\mathrm{MgO}$ versus $\mathrm{SiO}_{2}$ (Fig. 4A), em que os tipos alcalinos se destacam pelos valores elevados dessa razão. A evolução entre fácies é marcada por declínio de $\mathrm{Al}_{2} \mathrm{O}_{3}, \mathrm{MgO}$ e $\mathrm{CaO}$, e menor variação de $\mathrm{FeO}_{\mathrm{t}}$ e $\mathrm{TiO}_{2}$, o que resulta no crescimento do índice agpaítico-IAG e decréscimo do número de magnésio-mg (Fig. 4B).

Apesar das variações na composição dos termos do núcleo se acomodarem segundo a mesma tendência, ocorre dispersão de valores e o comportamento particular de alguns óxidos, como $\mathrm{FeO}_{\mathrm{t}}$ e $\mathrm{TiO}_{2}$ (Fig. 5). Isto sugere a atuação de outros processos de diferenciação além do simples fracionamento mineral, permitindo propor que $\mathrm{BG}$ e $\mathrm{ABM}$ representam pulsos distintos de magmas cogenéticos. Nestes, $\mathrm{FeO}, \mathrm{e} \mathrm{TiO}$, tendem a crescer no sentido da diferenciação (Figs. 5A-B), porém os monzogranitos exibem menor $\mathrm{FeO}_{\mathrm{t}} / \mathrm{MgO}$ para valores equivalentes de $\mathrm{SiO}_{2}$ 


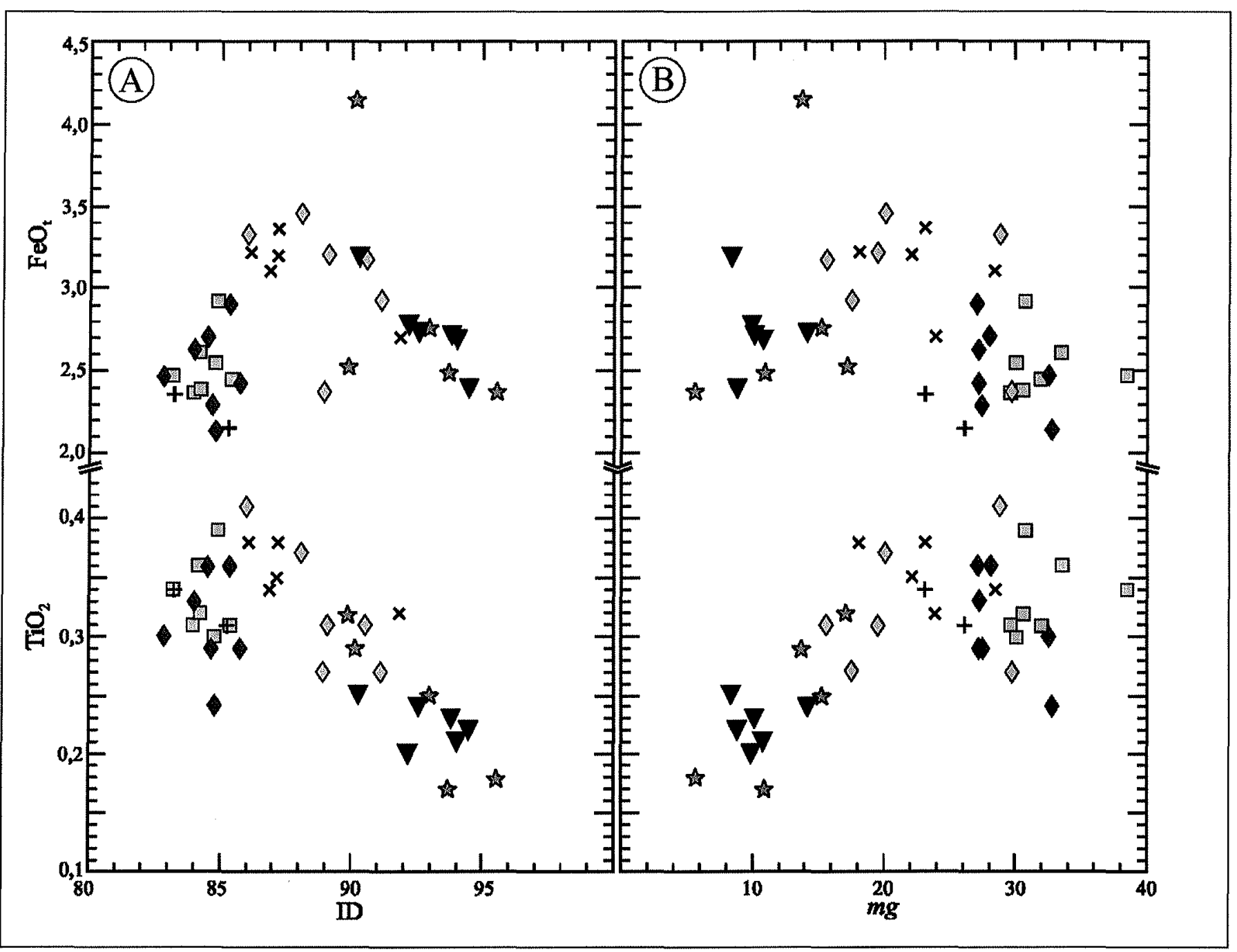

Figura 5-Comportamento de $\mathrm{FeOt}$ e $\mathrm{TiO}_{2}$ nos granitos do CILS (Nardi 1984, Gastal 1998), tendo como índice de diferenciação: $A-I D(=Q+A b+O r)$ normativo, e $B-m g$ ( $n^{\circ}$ de magnésio). Símbolos como na figura 3.

(Fig. 4A), justificando os maiores percentuais de máficos desta fácies (Tab. 1, Fig. 3B). O ABS, contudo, exibe maiores analogias com os granitos alcalinos (Figs. 5), contrário do registrado pela composição dos silicatos máficos (Gastal \& Lafon 2006). Comparado ao ABM, este exibe maior ID (Fig. 5A-B) e FeO/ $\mathrm{MgO}$ (Fig. 4A). Os granitos alcalinos (BAS e PG) exibem trends compatíveis com o fracionamento de $\mathrm{Pl}$ e fases máficas ricas em $\mathrm{Mg}$, de modo que, no sentido da evolução ocorre o crescimento de $I A G$ e Fe* $(=\mathrm{Fe} /(\mathrm{Fe}+\mathrm{Mg})$ ), conduzindo a líquidos residuais levemente peralcalinos. Nestes, $\mathrm{TiO}_{2}$ e $\mathrm{FeO}_{1}$ decrescem regularmente com a diferenciação (Figs. 5A-B).

Suscetibilidade magnética. Todos os granitos do complexo intrusivo classificam-se como da série magnetita (Ishihara 1981), ou ferromagnéticos (Bouchez 2000), com suscetibilidade magnética-k, na maioria dos casos, superior a $2,710^{-3} \mathrm{SI}$ (Fig. 6). Em afloramentos intemperizados, os valores de $\mathrm{k}$ são baixos, e isto é relevante no $\mathrm{PG}$. $\mathrm{O}$ histograma para o conjunto de fácies evidencia a distribuição multimodal dos valores de $\mathrm{k}$. Tal distribuição é comum aos granitos ferromagnéticos em face de variações na proporção entre os minerais paramagnéticos (silicatos máficos e ilmenita) e magnetita, ou de heterogeneidades texturais (Borradaile \& Henry 1997). Os dois picos de frequiência ( $\sim 5-6$ e 8-9 $10^{-3} \mathrm{SI}$ ) coincidem com a moda principal dos grupos com valores extremos de $\mathrm{k}$, respectivamente $\mathrm{BG}$ e granitos alcalinos
(Figs. 6A e C). No entanto, estes não equivalem à média de cada grupo, em face da dispersão ocasionada pela alteração ou variações texturais. Os granitos híbridos exibem amplo intervalo de $\mathrm{k}$, superpondo-se aos dois extremos. Apesar disto, as médias de $\mathrm{k}$ por afforamento crescem de granodiorito $\left(4,310^{-3} \mathrm{SI}\right)$, para granitos híbridos $\left(6,410^{-3} \mathrm{SI}\right)$ e alcalinos $\left(7,210^{-3} \mathrm{SI}\right)$.

São individualizadas três zonas magnéticas no pluton (Fig. 7A), cujos limites foram escolhidos de modo a melhor separar, respectivamente, as porções intensamente alteradas $\left(<410^{-3}\right.$ SI) nos granitos alcalinos e BG (Figs. 6A-C), e os dois termos extremos. Desta forma, este mapa magnético traduz a zonalidade concêntrica do pluton granítico, em que BG e ABM exibem valores baixos de $\mathrm{k}$, e os termos alcalinos e o ABS os mais elevados (Fig. 6A). Tal distribuição é também evidenciada pelas médias de $\mathrm{k}$ medida em rocha sã, que melhor discriminam os dois tipos híbridos (Tab. 2): k média de $\sim 5,510^{-3}$ SI no ABM, e de $7,710^{-3}$ SI no ABS. A faixa de direção NE-SW, no centro do corpo, se destaca entre as porções mais oxidadas com $\mathrm{k}<410^{-3}$ SI. Esta corresponde a importante zona de falha, como mostrado na figura $1 \mathrm{~B}$. O padrão circular dos valores de $\mathrm{k}$ no corpo granítico é consistente com os dados aeromagnéticos, que revelam um baixo magnético central (Fig. 7B), coincidente com as principais raízes alimentadoras da intrusão (Gastal et al. 2006). 


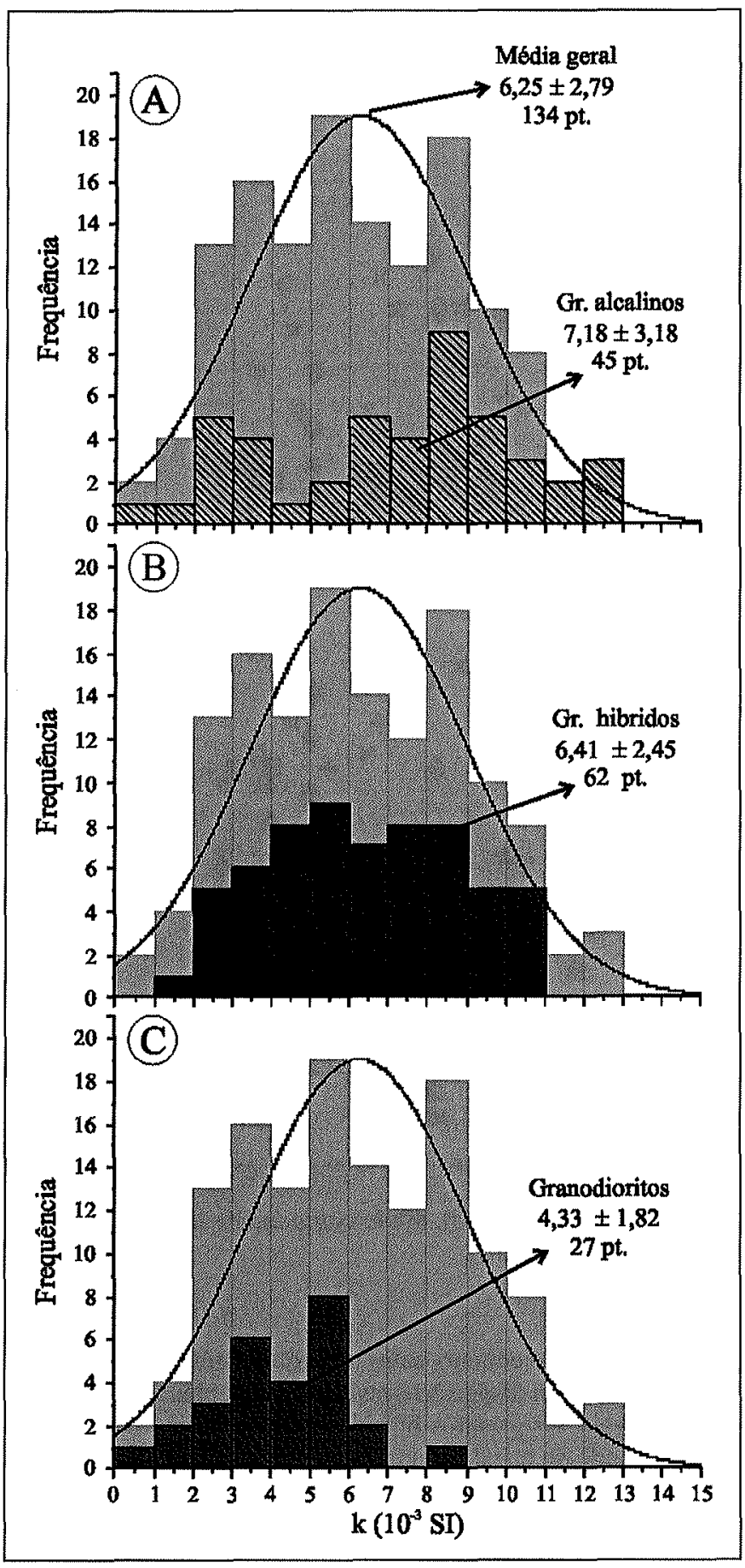

Figura 6 - Histogramas de valores médios, por afloramento, de suscetibilidade magnética $-k$, discriminando os principais conjuntos de granitos do complexo intrusivo Lavras do Sul - CILS: A - alcalinos, $B$ - hibridos, e C-granodioritos. Cinza claro, ao fundo, corresponde ao histograma de freqüência de todos os afloramentos com a curva de probabilidade relativa; são mostrados as médias e desvio padrão (2), e o número de afloramentos.

A correlação de $\mathrm{k}$ (rocha sã) com a moda e química em RT realça algumas particularidades (Figs. $8 \mathrm{~A}-\mathrm{B}$ ). O crescimento da $\mathrm{k}$ com a diferenciação é definido pela correlação negativa desta com o conteúdo de plagioclásio (Pl), e maior dispersão é observada com o índice de diferenciação (ID). Embora ocorra a tendência ao crescimento de $\mathrm{k}$ com o aumento de $\mathrm{FeO}$ e conteúdo de opacos, a dispersão é grande. Entre os termos do nú-

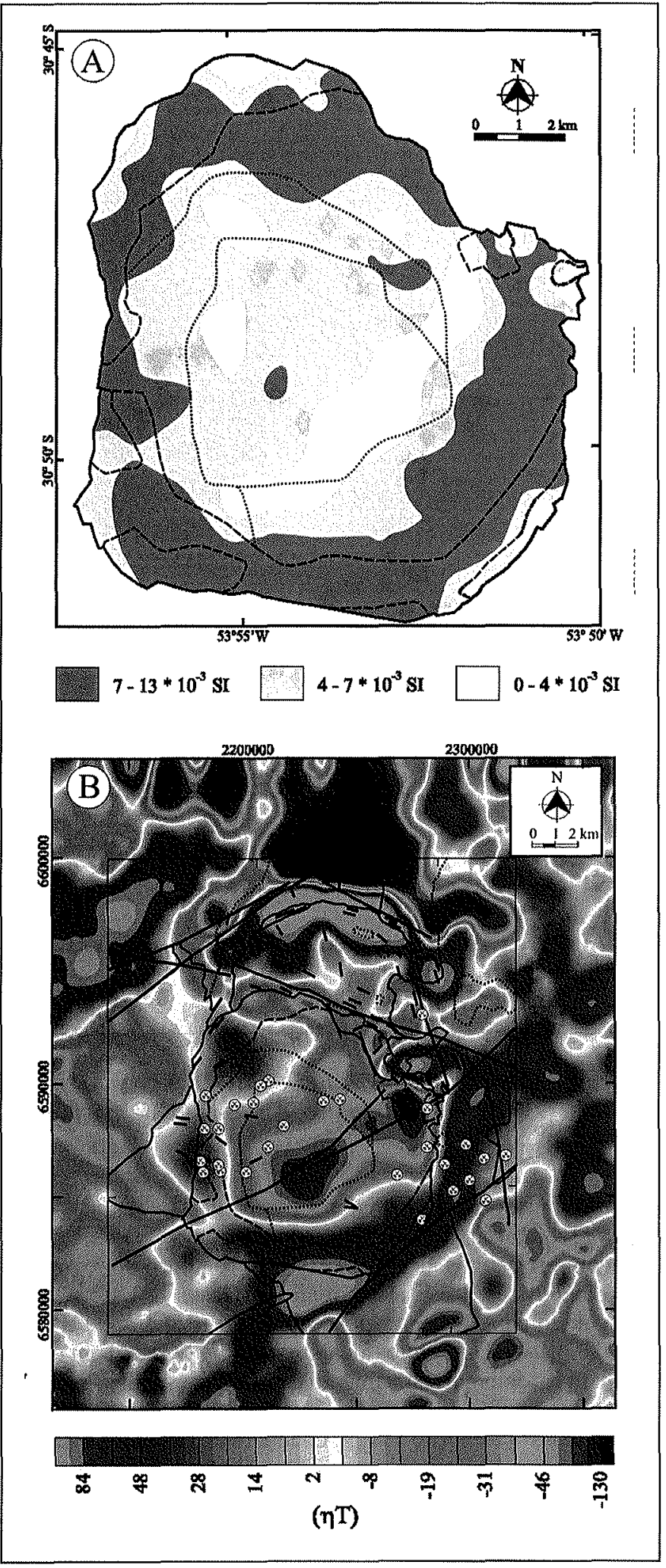

Figura 7-A - Mapa de zonas magnéticas do pluton granítico do CILS de acordo com as curvas mostradas na figura 2. B Mapa de anomalias magnéticas com redução ao pólo, para a região do CILS (Ferreira et al. em preparação).

cleo, com ID constante, a $\mathrm{k}$ aumenta de $\mathrm{BG}$ para ABM. Isto está aparentemente relacionado à natureza mais máfica dos últimos, como sugerido no diagrama $M v s$. $\mathrm{k}$ (Figs. 8A). A dispersão de valores de $\mathrm{k}$ nos granitos alcalinos se deve a maior variação no conteúdo de opacos e máficos. Do BAS para o PG equigranular, 
Tabela 2 - Valores médios de suscetibilidade magnética - k, em rocha sã, para os granitos do complexo intrusivo.

\begin{tabular}{|c|c|c|}
\hline Unidade/fácies & $\mathrm{k}\left(10^{-3} \mathrm{SI}\right)$ & $n^{\circ}$ pto. \\
\hline \multicolumn{3}{|l|}{ Granitos alcalinos } \\
\hline \multicolumn{3}{|l|}{ Pertita granito - $\mathrm{PG}$} \\
\hline Equigranular & $9,37 \pm 1,97$ & 12 \\
\hline Seriado & $9,05 \pm 1,79$ & 9 \\
\hline Sienogranito - BAS & $9,68 \pm 1,46$ & 14 \\
\hline \multicolumn{3}{|l|}{ Granitos do núcleo } \\
\hline \multicolumn{3}{|l|}{ Híbridos } \\
\hline Sienogranito - ABS & $7,71 \pm 1,79$ & 38 \\
\hline Monzogranito - ABM & $5,45 \pm 1,57$ & 21 \\
\hline \multicolumn{3}{|l|}{ Granodioritos - BG } \\
\hline Seriado & $4,36 \pm 1,58$ & 17 \\
\hline Porfiritico & $5,35 \pm 1,35$ & 8 \\
\hline
\end{tabular}

$\mathrm{k}$ e opacos aumentam paralelo ao decréscimo de máficos $(\mathrm{M})$, $m g$ e FeO (Figs. 8A-B).

Composição de silicatos máficos A evolução na composição de anfibólios e biotita é concordante e caracterizada por variações no conteúdo de $\mathrm{FeO}_{\mathrm{t}}, \mathrm{MgO}$ e $\mathrm{Al}_{2} \mathrm{O}_{3}$, que acompanham a geoquímica dos granitos e traduzem o crescimento de alcalinidade e razão $\mathrm{Fe}^{*}$. Essa razão e o índice agpaítico - IAG $\left(=\left(\mathrm{Na}_{2} \mathrm{O}+\mathrm{K}_{2} \mathrm{O}\right) / \mathrm{Al}_{2} \mathrm{O}_{3}\right.$, em \% mol.), em especial do anfibólio, são bons discriminantes para os dois grupos de granitos do CILS (Tab. 3). Naqueles do núcleo, os dois índices são moderados a baixos, e nos alcalinos são mais elevados e crescentes com a diferenciação. As razões $\mathrm{Fe}^{*}$ das duas fases máficas são equivalentes em uma mesma amostra, e maiores divergências ocorrem em relação à razão $\mathrm{Fe}^{*}{ }_{\mathrm{RT}}$ (Figs. 9A-B).

Nos granitos do núcleo, as razões $\mathrm{Fe}^{*}$ de biotita e anfibólio permanecem constantes ou decrescem suavemente com o aumento de Fe* ${ }_{\mathrm{RT}}$ (Figs. 9A-B). Tal comportamento acompanha a diferenciação de cada fácies, traduzindo variações significativas nas condições de $\mathrm{fO}_{2}$ durante os estágios magmático ou

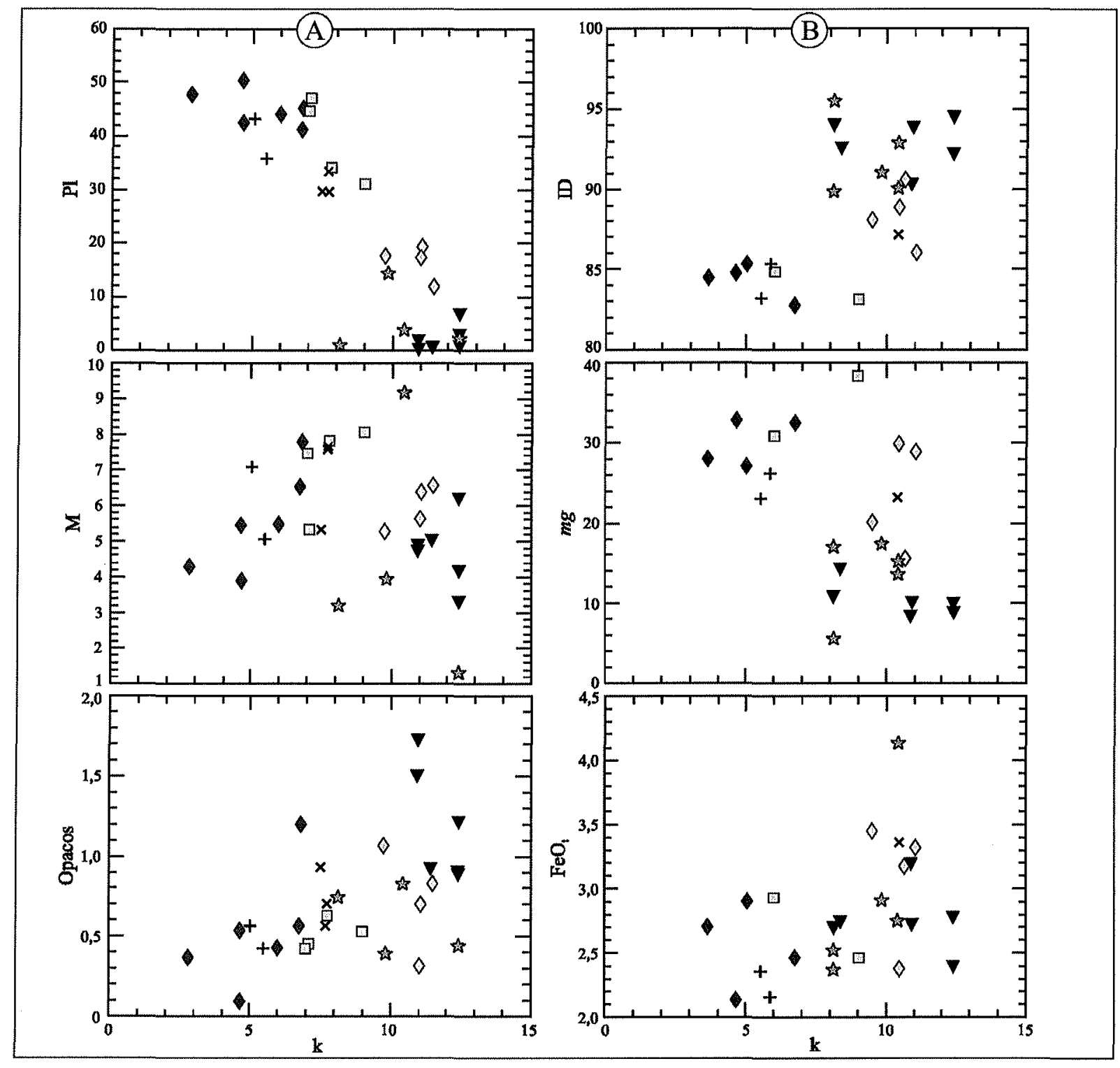

Figura 8-Diagramas de correlação da susceptibilidade magnética - $k$ (10-3 SI) com a composição dos granitos do complexo intrusivo: A-Modas: plagioclásio (Pl), $M$-índice de cor e opacos; $e$ B-Composição química (RT): índice de diferenciação (ID), número de magnésio (mg) e FeOt. Símbolos como na figura 3. 
Tabela 3 - Sintese de feições petrográficas, suscetibilidade magnética, e condiçães de cristalização para os granitos do complexo intrusivo Lavras do Sul.

\begin{tabular}{|c|c|c|c|c|}
\hline & \multicolumn{2}{|c|}{ Granitos do núcleo } & \multicolumn{2}{|c|}{ Granitos alcalinos } \\
\hline & Granodiorito & Granito híbrido & Sienogranito & Pertita granito \\
\hline \multicolumn{5}{|c|}{ Texturas e mineralogia } \\
\hline & $\begin{array}{l}\text { Seriado a porfiritico, grossso a fino. } \\
\text { Contrastes texturais e feições de exsolução } \\
\text { de voláteis. } \\
\text { Zonação oscilatória do } \mathrm{Pl} \text { (An 35-20). }\end{array}$ & $\begin{array}{l}\text { Seriado grosso a fino. } \\
\text { Feições de dissolução/corrosão do Pl e de } \\
\text { hibridismo freqüentes nos monzogranitos, } \\
\text { e escassas nos sienogranitos. }\end{array}$ & $\begin{array}{l}\text { Bimodalidade textural (grossa e média). } \\
\text { Feições de hibridismo restritas. } \\
\text { Reabsorção do Pl pelo Kfs. }\end{array}$ & $\begin{array}{l}\text { Equigranular médio ou grosso: agregados } \\
\text { de Kfs ou Qtz, transição subsolvus para } \\
\text { hipersolvus. } \\
\text { Seriado grosso a fino: reabsorção do Pl pelo } \\
\text { Kfs. }\end{array}$ \\
\hline Bt:Amp. & $\geq 2: 1$ & 2:1 (monzogr.) a 1:1 (sienogr.) & $<1: 1$ & $<1: 1$ \\
\hline Anfibólio & $\begin{array}{l}\text { Fe-hornblenda liquidus (Fe-edenita e Mg- } \\
\text { hornblenda) }\end{array}$ & Fe-hornblenda liquidus (Mg-hornblenda) & Fe-hornblenda magmática (Fe-edenita) & $\begin{array}{l}\text { Fe-hornblenda (seriado) a Fe-barroisita } \\
\text { (equigranular), tardi-magmática a } \\
\text { subsolidus }\end{array}$ \\
\hline $\mathrm{Fe}^{* 1}$ & $0,55-0,56$ & $0,59-0,57$ & $0,69-0,87$ & $0,76-0,87$ \\
\hline $\mathrm{IAG}^{1}$ & $0,44-0,51$ & $0,44-0,56$ & $0,66-0,77$ & $0,66-0,90$ (seriado) e $0,99-1,36$ (equigr.) \\
\hline Biotita & Fe-biotita magmática & Fe-biotita magmática & Fe-biotita tardi-magmática & $\begin{array}{l}\text { Fe-biotita/anita tardi-magmática (seriado) a } \\
\text { subsolidus (equigranular) }\end{array}$ \\
\hline $\mathrm{Fe}^{* 1}$ & $0,56-0,60$ & $0,58-0,62$ & $0,66-0,67$ & $0,73-0,94$ \\
\hline Titanita & Escassa e subsolidus & Tardi-magmática & Primária e rica em ETR-Nb-Y & $\begin{array}{l}\text { Primária e rica em ETR-Nb-Y é ocasional } \\
\text { no tipo seriado }\end{array}$ \\
\hline$M(\%)^{2}$ & $5,6-6,1$ & $7,2-6,9$ & 6 & $4,5-4,3$ \\
\hline \multicolumn{5}{|c|}{ Óxidos de Fe-Ti e susceptibilidade magnética } \\
\hline Opacos $(\%)^{2}$ & $0,53-0,50$ & $0,51-0,73$ & 0,73 & $0,61-1,06$ \\
\hline Ti-Mt:Ilm & 3:1 a $5: 1$ & $10: 1$ & $\geq 20: 1$ & $\geq 20: 1$ \\
\hline $\mathrm{k}\left(10^{-3} \mathrm{SI}\right)^{3}$ & 4,36 a 5,35 & 5,45 a 7,71 & 9,68 & 9,05 a 9,37 \\
\hline \multicolumn{5}{|c|}{ Condições de cristalização } \\
\hline $\mathrm{P}(\mathrm{kbar})^{4}$ & $2-3$ & 4 (monzogranito) e 2-3 (sienogranito) & $2-3$ & $\sim 1$ \\
\hline $\mathrm{H}_{2} \mathrm{O}(\%)^{5}$ & $3-4$ & $3-4$ & 2 & 1 \\
\hline Liquidus $^{5}$ & $950-900^{\circ} \mathrm{C}$ & $900-870^{\circ} \mathrm{C}$ & $970-950^{\circ} \mathrm{C}$ & $970-950^{\circ} \mathrm{C}$ \\
\hline Solidus ${ }^{5}$ & $760-750^{\circ} \mathrm{C}$ & $750-720^{\circ} \mathrm{C}$ & $750-720^{\circ} \mathrm{C}$ & $670-650^{\circ} \mathrm{C}$ \\
\hline
\end{tabular}




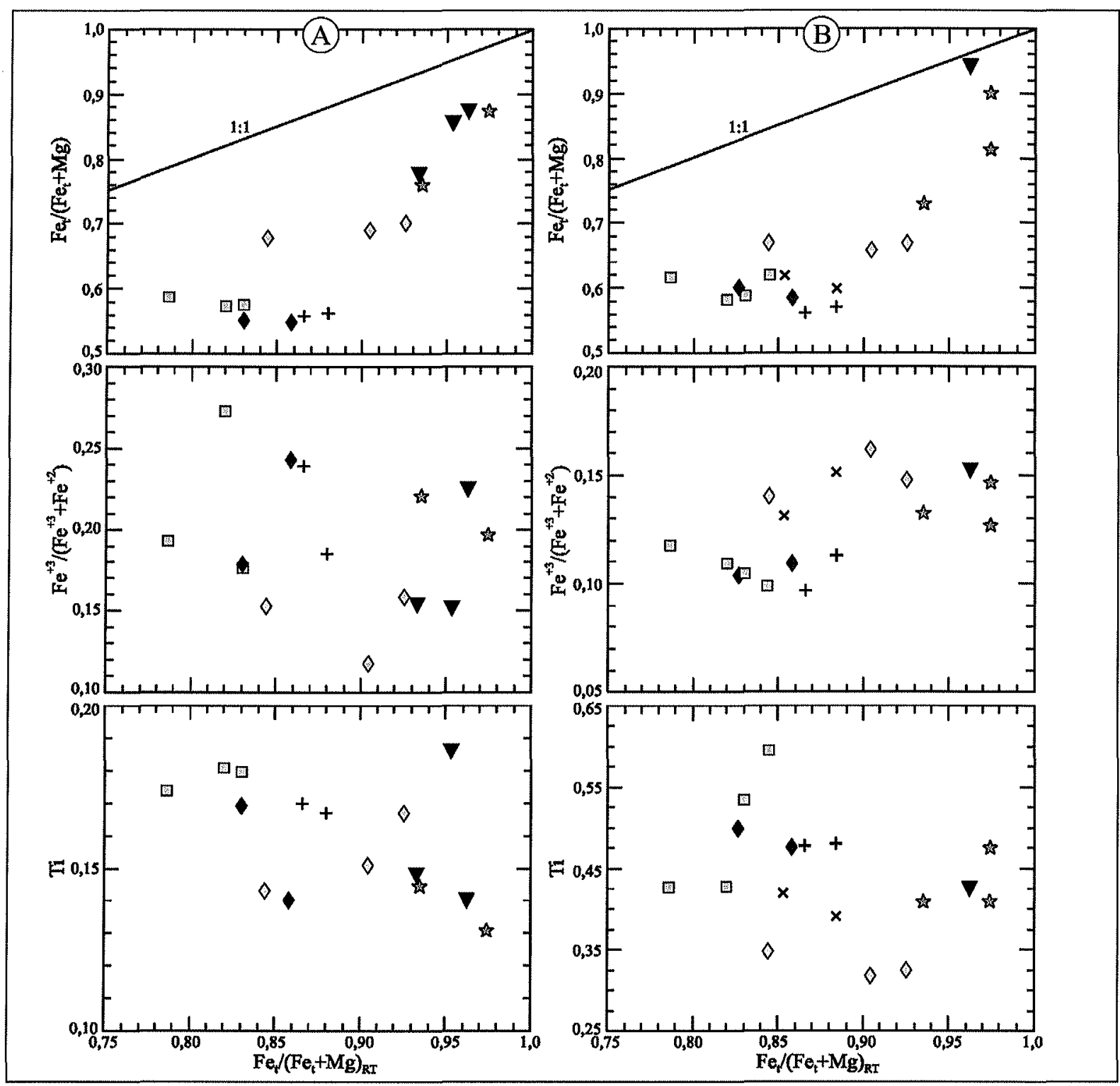

Figura 9-Comportamento de Fet/(Fet $+\mathrm{Mg}), \mathrm{Fe}+3 /(\mathrm{Fe}+2+\mathrm{Fe}+3)$ e Ti de: A - anfibólios e B - biotita, relativo a química dos granitos do CILS (RT). Razão Fe+3/Fe+2 estimada para as duas fases (Gastal 2004): esquema de normalização 13 eCNK (somatório de cátions, exceto $\mathrm{Ca}, \mathrm{Na}$ e K, igual a 13) para o anfibólio, e cálculo empírico em função da composição da biotita, segundo Bruyin et al. (1983, in Salonsaari 1995). Símbolos como na figura 3.

pós-magmático (Czamanske et al. 1981). Maiores contrastes ocorreram no $\mathrm{BG}$, em que a Ilm precoce na cristalização é mais abundante (Tab. 1). A grande dispersão nos valores de $\left(\mathrm{Fe}^{+3}\right)^{*}$ $\left(=\mathrm{Fe}^{+3} /\left(\mathrm{Fe}^{+3}+\mathrm{Fe}^{+2}\right)\right)$ no anfibólio, para pequenas variações de $\mathrm{Fe}^{*}{ }_{\mathrm{AMP}}$ (Fig. 9A) $\mathrm{e}^{\mathrm{IV}} \mathrm{Al}_{\mathrm{AMP}}$ (não mostrado), melhor registram as variações de $f \mathrm{O}_{2}$. A biotita destes granitos, exceto $\mathrm{ABS}$, exibe $\left(\mathrm{Fe}^{+3}\right)^{*}$ constante, indicando condições de $f \mathrm{O}_{2}$ tamponadas ou o re-equilíbrio no estágio tardi- a pós-magmático, como sugere a maior dispersão de $\mathrm{Ti}_{\mathrm{BT}}$ (Fig. 9B). A natureza particular do ABS é também indicada pela biotita. Nesta, ${ }^{1 V} \mathrm{Al}$ é mais baixo, e o $\left(\mathrm{Fe}^{+3}\right)^{*}$ elevado e similar ao de biotita dos termos alcalinos (Fig. 9B). Apesar de incertezas na estimativa de $\mathrm{Fe}^{+3} / \mathrm{Fe}^{+2}$, isto está de acordo com a natureza mais tardia da biotita na cristalização, e equilíbrio em condições de $\mathrm{fO}_{2}$ distintas.

As razões $\mathrm{Fe}^{*}$ das duas fases máficas, nos granitos alcalinos, crescem com a diferenciação (a convergência é maior quando se usam as razões dos óxidos de elementos). Isto é mais acentuado na biotita (Figs. 9A-B), de modo que o coeficiente de partição-Kd $(\mathrm{Fe} / \mathrm{Mg})^{\mathrm{BT} / \mathrm{AMP}}$ aumenta neste sentido. Tal comportamento é con- sistente com o decréscimo de ${ }^{\mathrm{IV}} \mathrm{Al}$, $\mathrm{o}$ que favorece a partição do Fe na biotita (Speer 1984). No BAS, o maior contraste entre as razões $\mathrm{Fe}^{*}$ de minerais e rocha indica modificações menores nas condições de $\mathrm{O}_{2}$, atribuídas a processos localizados. A evolução na composição do anfibólio é marcada por aumento de $\left(\mathrm{Fe}^{+3}\right)^{*} \mathrm{e}$ Mn e descréscimo de ${ }^{\mathrm{IV}} \mathrm{Al}$. $\mathrm{O} \mathrm{Ti}_{\mathrm{AMP}}$ tende a decrescer, acompanhando a geoquímica da rocha, apesar da dispersão observada no diagrama $\mathrm{Ti}_{\mathrm{AMP}} v s . \mathrm{Fe}^{*}{ }_{\mathrm{RT}}$ (Fig. 9A). Isto é consistente com a cristalização mais tardia do anfibólio. $\mathrm{Na}$ biotita, $\left(\mathrm{Fe}^{+3}\right)^{*}$ permanece constante, porém os valores são mais elevados que os da biotita dos termos do núcleo (Fig. 9B), indicando condições tamponadas e maior $\mathrm{OO}_{2} . \mathrm{Ti}_{\mathrm{BT}}$ cresce com a diferenciação, para pequenas variações de ${ }^{\mathrm{IV}} \mathrm{Al}_{\mathrm{BT}}$, de modo que a biotita registra o equilíbrio em condições magmáticas, embora as texturas indiquem que é tardia ou subsolidus. Nestes granitos, ao contrário daqueles do núcleo, o equilíbrio entre fases máficas é o principal controle das condições de $f \mathrm{O}_{2}$. Isto conduziria ao decréscimo de $\mathrm{O}_{2}$ com a diferenciação e, conseqüentemente, a biotita mais ferrosa e a presença de Ilm tardi-magmática. No entanto, a correlação negativa entre a moda 
de biotita e opacos (Fig. 3D), sendo os últimos dominantemente Ti-Mt, é contraditória com esta trajetória redox se a pressão foi mantida constante durante a cristalização. Percentuais crescentes de Ti-Mt com a diferenciação (Fig. 3C, Tab. 1), neste caso, indicam cristalização em condições sucessivamente mais rasas, uma vez que o decréscimo da pressão desestabiliza a biotita (Wones \& Eugster 1965).

As variações na composição da titanita também diferenciam os dois grupos de granitos (Gastal \& Lafon 2006). No BG e $\mathrm{ABM}$, a titanita se aproxima da composição ideal exibindo menor $\mathrm{Fe}^{+3}$ e $\mathrm{Al}$, enquanto nos termos alcalinos e $\mathrm{ABS}$, o conteúdo de $\mathrm{Fe}^{+3}$ é mais elevado.

\section{ÓXIDOS DE FE-TI}

Texturas Os óxidos de Fe-Ti, nos granitos do núcleo, estão distribuídos de modo heterogêneo estando associados a concentrações de máficos. Os percentuais de opacos estão na faixa de $0,4-0,7 \%$ e, apesar da dispersão no BG seriado (Tab. 1), o decréscimo de opacos acompanha o índice de cor (Fig. 3C). Grãos de Ti-Mt e Ilm precoces na cristalização são freqüentes junto a agregados de Pl e anfibólio (tipo A ou B), em especial, no BG seriado. Ti-Mt tardi-magmática ou subsolidus é comum, enquanto a ilmenita subsolidus é restrita a alteração de anfibólio e biotita. Hematita extremamente fina ocorre na matriz do BG porfirítico. A proporção de Ti-Mt:Ilm cresce no sentido da evolução, de 3:1 a 5:1 nos granodioritos para 10:1 nos termos híbridos (Tab. 1). Isto se deve a desestabilização da Ilm precoce, o que aparentemente traduz cristalização em condições mais oxidantes uma vez que o conteúdo de $\mathrm{TiO}_{2}$ é similar nos dois conjuntos de fácies (Figs. 5A-B). Treliças, inclusões compostas e lamelas sanduíche ocorrem nos grãos de Ti-Mt maiores e precoces na cristalização (tipo A ou B). A martita é comum em amostras situadas próximo às principais zonas de falha. Neste caso, a martita corresponde à transformação de Mt para hematita, que ocorre em anéis na borda ou em manchas no interior dos grãos. A hematita substitui a Ilm em treliças e lamelas sanduíche de amostras mais intensamente oxidadas, nas quais observa-se a transformação parcial de grãos de Ilm para rutilo.

Nos granitos alcalinos, o conteúdo de opacos é variado e tende a crescer no sentido da diferenciação (Tab. 1, Fig. 3C). Percentuais mais baixos $(0,3-0,5 \%)$ caracterizam o $\mathrm{PG}$ seriado. Nos demais, os percentuais são mais elevados $(>0,5 \%)$ e mostram correlação negativa com o conteúdo de biotita (Fig. 3D). Apesar disto, os óxidos de Fe-Ti estão homogeneamente distribuídos, ocorrendo também em grãos isolados e intergranulares. Ti-Mt é muito comum em grãos desenvolvidos (tipos A e B), e também tardi-magmáticos ou subsolidus (tipo C). Os últimos ocorrem associados a albita tardia e pertitas. A proporção Ti-Mt: Ilm é elevada ( $>20: 1$ ) na maioria das amostras (Tab. 1). Considerando o conteúdo mais elevado de $\mathrm{TiO}_{2}$ no BAS (Figs. 5A-B), é possível sugerir condições mais oxidantes durante sua cristalização de modo a justificar a desestabilização da Ilm. Do BAS para o $\mathrm{PG}$, o efeito do fracionamento e descompressão parece ter sido preponderante, como já referido. Em duas amostras do PG, particularidades texturais justificam a maior abundância da Ilm (Tab. 1), que é precoce e ocorre em autólitos no PG seriado,

Tabela 4-Análises químicas representativas de Ti-magnetita dos granitos do complexo intrusivo Lavras do Sul.

\begin{tabular}{|c|c|c|c|c|c|c|c|c|c|c|c|c|c|c|c|}
\hline & \multicolumn{15}{|c|}{ Granitos do núcleo } \\
\hline & \multicolumn{5}{|c|}{ Granodiorito seriado } & \multicolumn{3}{|c|}{ Granodiorito porfiritico } & \multicolumn{4}{|c|}{ Monzogranito híbrido } & \multicolumn{3}{|c|}{ Sienogranito híbrido } \\
\hline & \multirow{2}{*}{$\begin{array}{c}\text { A } \\
M 640 / 27\end{array}$} & \multicolumn{2}{|c|}{$\mathrm{B}$} & \multicolumn{2}{|c|}{$\mathrm{C}$} & \multirow{2}{*}{$\begin{array}{c}\mathrm{A} \\
\mathrm{M} 642 / 29\end{array}$} & \multirow{2}{*}{$\begin{array}{c}\mathrm{B} \\
\mathrm{M} 642 / 31\end{array}$} & \multirow{2}{*}{$\begin{array}{c}\mathrm{C} \\
\mathrm{M} 642 / 24^{*}\end{array}$} & \multirow{2}{*}{$\begin{array}{c}\text { A } \\
\text { M98/5 }\end{array}$} & \multirow{2}{*}{$\begin{array}{c}\text { B } \\
\mathrm{M} 98 / 11 \\
\end{array}$} & \multirow{2}{*}{$\begin{array}{c}C \\
M 675 / 35^{*}\end{array}$} & \multirow[b]{2}{*}{ M675/44 } & \multirow{2}{*}{$\begin{array}{c}\mathrm{A} \\
672 \mathrm{M} 19 \\
\end{array}$} & \multicolumn{2}{|c|}{$\mathrm{B}$} \\
\hline & & $640 \mathrm{M} 3$ & $\mathrm{M} 152 / 47^{*}$ & $\mathrm{M} 640 / 22$ & M152/41* & & & & & & & & & $672 \mathrm{M} 18$ & $672 \mathrm{M} 20$ \\
\hline $\mathrm{SiO}_{2}$ & 0,04 & 0,04 & 0,04 & 0,06 & 0,04 & 0,03 & 0,04 & 0,09 & 0,07 & 0,04 & 0,04 & 0,07 & 0,04 & 0,06 & 0,02 \\
\hline $\mathrm{TiO}_{2}$ & 1,10 & 0,53 & 0,05 & 0,12 & 0,45 & 0,30 & 3,06 & 0,07 & 0,18 & 0,38 & 0,11 & 0,31 & 2,34 & 0,11 & 0,47 \\
\hline $\mathrm{Al}_{2} \mathrm{O}_{3}$ & 0,37 & 0,15 & 0,07 & 0,06 & 0,07 & 0,24 & 0,39 & 0,05 & 0,10 & 0,13 & 0,11 & 0,15 & 0,12 & 0,05 & 0,11 \\
\hline $\mathrm{Cr}_{2} \mathrm{O}_{3}$ & 0,03 & 0,05 & 0,06 & 0,10 & 0,01 & 0,03 & 0,07 & 0,04 & 0,04 & 0,04 & 0,06 & 0,09 & 0,06 & 0 & 0,05 \\
\hline $\mathrm{Fe}_{2} \mathrm{O}_{3}$ & 67,24 & 69,29 & 68,71 & 68,95 & 67,94 & 67,80 & 62,65 & 67,86 & 68,16 & 68,31 & 68,81 & 68,11 & 65,05 & 70,10 & 69,55 \\
\hline $\mathrm{FeO}$ & 32,55 & 32,30 & 31,10 & 31,29 & 31,42 & 31,24 & 33,79 & 30,89 & 31,20 & 31,56 & 31,22 & 31,46 & 33,65 & 31,78 & 32,24 \\
\hline $\mathrm{MnO}$ & 0,04 & 0,02 & 0,03 & 0,06 & 0,03 & 0,02 & 0,22 & n.d. & n.d. & 0,01 & 0,04 & 0,01 & 0 & 0,09 & 0,04 \\
\hline $\mathrm{MgO}$ & n.d. & 0 & n.d. & 0 & 0 & n.d. & 0 & 0 & n.d. & 0 & 0,02 & 0,01 & 0,01 & 0,01 & 0,01 \\
\hline $\mathrm{CaO}$ & n.d. & 0,01 & 0,04 & 0,09 & 0,05 & 0,03 & 0,05 & 0,02 & 0,04 & 0,04 & 0,04 & 0,02 & 0,01 & 0,03 & n.d. \\
\hline Total & 101,36 & 102,39 & 100,10 & 100,74 & 100,02 & 99,69 & 100,27 & 99,02 & 99,78 & 100,50 & 100,44 & 100,23 & 101,27 & 102,24 & 102,48 \\
\hline \multicolumn{16}{|c|}{ Membros finais (\% mol.) } \\
\hline Usp & 3,00 & 1,50 & 0,25 & 0,25 & 1,25 & 1,00 & 8,74 & 0,25 & 0,50 & 1,00 & 0,25 & 1,00 & 6,73 & 0,25 & 1,25 \\
\hline $\mathrm{Mt}$ & 95,88 & 97,76 & 99,25 & 99,25 & 98,38 & 98,50 & 90,01 & 99,25 & 99,00 & 98,50 & 99,13 & 98,25 & 92,64 & 99,38 & 98,37 \\
\hline
\end{tabular}

\begin{tabular}{|c|c|c|c|c|c|c|c|c|c|c|c|c|c|c|c|}
\hline & \multicolumn{15}{|c|}{ Granitos alcalinos } \\
\hline & \multicolumn{5}{|c|}{ Sienogranito } & \multicolumn{5}{|c|}{ Pertita granito seriado } & \multicolumn{5}{|c|}{ Pertita granito equigranular } \\
\hline & \multicolumn{2}{|r|}{$\mathrm{A}$} & B & \multicolumn{2}{|c|}{ C } & \multirow{2}{*}{$\begin{array}{c}\text { A } \\
\text { M109.31 }\end{array}$} & \multicolumn{3}{|c|}{$\mathrm{B}$} & \multirow{2}{*}{$\begin{array}{c}\mathrm{C} \\
\mathrm{M} 109-37 \\
\end{array}$} & \multirow{2}{*}{$\begin{array}{c}\text { A } \\
\text { M399-8 }\end{array}$} & \multicolumn{3}{|c|}{ B } & \multirow{2}{*}{$\begin{array}{c}\mathrm{C} \\
\mathrm{M} 399-2 \\
\end{array}$} \\
\hline & $\mathrm{M} 405-12$ & M405-15 & M405-17 & $\mathrm{M} 405-14$ & $405 \mathrm{M} 13$ & & M109-28* & $\mathrm{M} 109-30$ & M109-33 & & & M399-6 & M399-9 & $399 \mathrm{M} 23^{*}$ & \\
\hline $\mathrm{SiO}_{2}$ & 0,10 & 0,05 & 0,06 & 0,05 & 0,05 & 0,10 & 0,05 & 0,07 & 0,03 & 0,07 & 0,08 & 0,07 & 0,22 & 0,10 & 0,08 \\
\hline $\mathrm{TiO}_{2}$ & 0,76 & 2,62 & 1,63 & 3,24 & 0,66 & 4,66 & 0,38 & 4,98 & 1,28 & 0,69 & 1,63 & 2,91 & 1,70 & 0,36 & 0,21 \\
\hline $\mathrm{Al}_{2} \mathrm{O}_{3}$ & 0,13 & 0,32 & 0,17 & 0,14 & 0,13 & 0,36 & 0,11 & 0,17 & 0,08 & 0,15 & 0,05 & 0,08 & 0,05 & 0,06 & 0,04 \\
\hline $\mathrm{Cr}_{2} \mathrm{O}_{3}$ & 0,05 & 0,05 & 0,01 & 0,05 & 0,01 & 0,05 & n.d. & $0,0 \mathrm{l}$ & 0.02 & 0,04 & 0,02 & 0,02 & n.d. & 0,01 & 0,06 \\
\hline $\mathrm{Fe}_{2} \mathrm{O}_{3}$ & 67,84 & 63,62 & 65,87 & 62,76 & 69,55 & 57,25 & 67,00 & 57,92 & 65,73 & 66,65 & 65,52 & 63,50 & 64,36 & 66,19 & 66,14 \\
\hline $\mathrm{FeO}$ & 32,20 & 33,14 & 32,63 & 33,73 & 32,37 & 34,03 & 30,95 & 34,80 & 31,92 & 31,38 & 32,46 & 33,91 & 32,37 & 30,63 & 30,25 \\
\hline $\mathrm{MnO}$ & 0,03 & 0,54 & 0,21 & 0,46 & 0,04 & 0,62 & 0,04 & 0,48 & 0,09 & 0,05 & 0,17 & 0,03 & 0,14 & 0,04 & 0,05 \\
\hline $\mathrm{MgO}$ & n.d. & 0 & n.d. & n.d. & n.d. & n.d. & n.d. & n.d. & n.d. & 0 & n.d. & 0,03 & n.d. & 0,01 & 0,01 \\
\hline $\mathrm{CaO}$ & 0,01 & 0,02 & n.d. & 0.08 & 0,21 & 0 & 0,02 & 0,02 & n.d. & 0,06 & 0,01 & 0,02 & 0,06 & 0,01 & 0,05 \\
\hline Total & 101,12 & 100,36 & 100,58 & 100,51 & 103,01 & 97,08 & 98,55 & 98,44 & 99,15 & 99,09 & 99,93 & 100,56 & $98,91$. & 97,43 & 96,90 \\
\hline \multicolumn{16}{|c|}{ Membros finais $(\% \mathrm{~mol})}$. \\
\hline Usp & 2,24 & 7,49 & 4,75 & 9,24 & 1,75 & 13,73 & 1,00 & 14,52 & 3,76 & 2,00 & 4,75 & 8,26 & 5,01 & 1,00 & 0,75 \\
\hline $\mathrm{Mt}$ & 96,88 & 91,39 & 94,63 & 90,01 & 97,75 & 84,77 & 98,50 & 84,86 & 96,12 & 97,38 & 94,88 & 91,36 & 94,12 & 98,38 & 98,75 \\
\hline
\end{tabular}


e é tardi-magmática e associada a albita tardia e Fe-barroisita no PG equigranular: Microtexturas de oxi-exsolução e martita são feições escassas nestes granitos.

Composição química Os óxidos de Fe-Ti possuem composições evoluídas e similares nos dois grupos de granitos do complexo intrusivo (Tabs. 4-5), quais sejam: (a) Ti-Mt com baixo conteúdo de $\mathrm{Al}_{2} \mathrm{O}_{3}(0,1-0,3 \%)$ e de $\mathrm{Cr}_{2} \mathrm{O}_{3}$, este último abaixo do limite de deteç̧ão; e (b) Ilm com baixo $\mathrm{MgO}(<0,07 \%) \mathrm{e}$ conteúdo moderado de $\mathrm{MnO}(2-6 \%)$, similar ao de ilmenita de granitos mais redutores (Frost \& Lindsley 1991). Diferenças na composição da Ilm entre os granitos só são vistas no detalhe (Figs. 10A-B), e os maiores contrastes na Ti-Mt se devem a graus distintos de re-equilíbrio no final da cristalização (Fig. 10C). Este processo foi mais intenso nos termos do núcleo, nos quais a Ti-Mt se aproxima da composição ideal, com percentuais de Usp em média baixos (1-2\%). Nestes, a Ilm contém 4-6\% de $\mathrm{MnO}$, o que equivale a 9 a $11 \%$ da molécula de pirofanita. Além disso, nos tipos híbridos (ABM-ABS), a composição da $\mathrm{Ilm}$ desloca-se da linha base da série $\mathrm{Ilm}-\mathrm{Hem}_{\mathrm{sc}}$ indicando o efeito da oxidação subsolidus (Fig. 10B). Nos granitos alcalinos, a Ti-Mt exibe percentuais mais elevados e variados da molécula de Usp, em média superiores a 2-3\%, traduzindo o menor efeito do re-equilíbrio subsolidus. A Ilm, nestes granitos, exibe menor conteúdo de $\mathrm{MnO}$, ao redor de 2-4\%.

As variações na composição de Ti-Mt e Ilm, embora pequenas, estão de acordo com as feições texturais que indicam o maior efeito da oxidação pseudomórfica nos granitos do núcleo. Isto pressupõe a maior atividade de fluidos aquosos no estágio pós-magmático a temperaturas relativamente elevadas (600-500 ${ }^{\circ} \mathrm{C}$ ). Nos tipos alcalinos, estes processos teriam sido menos importantes, e a formação de Ti-Mt subsolidus, associada a albita tardia e pertitas, parece ser decorrente de líquidos residuais pobres em Ti e com T próximo a solidus $\left(670^{\circ}-650^{\circ} \mathrm{C}\right.$, Tab. 3).

\section{DISCUSSÃO}

Pluton granítico multicíclico A existência de dois grupos de granitos não comagmáticos no CILS, como referido por Nardi (1984), é referendada pela química de anfibólios, biotita, titanita e óxidos de $\mathrm{Fe}-\mathrm{Ti}$, que indicam também diferenças nas condições de pressão e oxi-redução durante a cristalização e resfriamento. Apesar da proximidade no grau de diferenciação destes granitos, a geoquímica e as idades isotópicas evidenciam evoluções distintas mesmo entre fácies de mesma afinidade. Isto sugere eventos multi-intrusivos envolvendo magmas não cogenéticos e em parte contemporâneos, de modo a justificar contatos gradativos ou a ausência de relações claras de intrusão.

Granitos do núcleo Outros processos de diferenciação além do fracionamento mineral foram importantes na evolução de BG e ABM-ABS, que representam pulsos distintos de magmas cogenéticos. Os desequilíbrios texturais registram situações diversas relacionadas a fronts de dissolução/interação de margens resfriadas ou de pulsos anteriores, já solidificados, por novo pulso de magma dacítico. Tal processo seria responsável por flutuações na composição (zonação oscilatória do $\mathrm{Pl}$ ) e saturação em voláteis (bolsões porfiríticos e feições associadas) do novo pulso de $B G$, bem como por feições de dissolução no monzogranito híbrido (ABM). Considerando os indicativos de pressão com base no Al do anfibólio, Gastal (2004) sugeriu que este processo de recarga teria promovido a ressurgência da intrusão central, originalmente formada pelo $\mathrm{ABM}$, de 4 para 2-3 kbars. A natureza precoce do anfibólio na cristalização indica percentual inicial elevado de $\mathrm{H}_{2} \mathrm{O}$ nestes magmas, da ordem de 3-4\% (Tab.

Tabela 5 - Análises químicas representativas de ilmenita e martita dos granitos do complexo intrusivo.

\begin{tabular}{|c|c|c|c|c|c|c|c|c|c|c|c|}
\hline & \multicolumn{6}{|c|}{ Granitos do núcleo } & \multicolumn{5}{|c|}{ Granitos alcalinos } \\
\hline & \multicolumn{2}{|c|}{$\begin{array}{l}\text { Granodiorito } \\
\text { seriado }\end{array}$} & \multirow{2}{*}{ 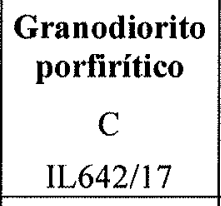 } & \multicolumn{3}{|c|}{ Monzogranito híbrido } & \multirow{2}{*}{\begin{tabular}{|c|} 
Sienogranito \\
B \\
IL405/8 \\
\end{tabular}} & \multicolumn{2}{|c|}{$\begin{array}{l}\text { Pertita granito } \\
\text { seriado }\end{array}$} & \multicolumn{2}{|c|}{$\begin{array}{c}\text { Pertita granito } \\
\text { equigranular }\end{array}$} \\
\hline & $\begin{array}{c}\text { A } \\
\text { IL640/3 }\end{array}$ & $\begin{array}{c}\text { B } \\
\mathrm{Mt} 152 / 50^{*}\end{array}$ & & $\begin{array}{c}\text { IC } \\
198 / 6\end{array}$ & $\begin{array}{c}\text { B } \\
198 / 4 \\
\end{array}$ & $\begin{array}{c}\mathrm{C} \\
198 / 5 \\
\end{array}$ & & $\begin{array}{c}\text { B } \\
\text { I109/12 }\end{array}$ & $\begin{array}{c}\text { C } \\
\text { I109/14 }\end{array}$ & $\begin{array}{c}\mathrm{A} \\
399 \mathrm{M} 25\end{array}$ & $\begin{array}{c}\text { B } \\
\text { IL 399/9 }\end{array}$ \\
\hline $\mathrm{SiO}_{2}$ & 0,03 & 0,06 & 0,04 & 0,08 & 0,02 & 0,01 & 0,01 & 0,00 & 0,01 & 0,02 & 0,01 \\
\hline $\mathrm{TiO}_{2}$ & 46,91 & 0,27 & 47,54 & 47,91 & 49,69 & 49,85 & 50,39 & 49,51 & 48,27 & 48,15 & 48,18 \\
\hline $\mathrm{Al}_{2} \mathrm{O}_{3}$ & n.d. & 0,11 & n.d. & n.d. & 0,01 & n.d. & 0,01 & 0,05 & 0,02 & n.d. & 0,02 \\
\hline $\mathrm{Cr}_{2} \mathrm{O}_{3}$ & n.d. & 0,34 & 0,01 & 0,01 & n.d. & 0,00 & 0,02 & 0,05 & n.d. & 0,05 & n.d. \\
\hline $\mathrm{Fe}_{2} \mathrm{O}_{3}$ & 9,63 & 99,79 & 8,09 & 10,31 & 5,94 & 5,17 & 4,10 & 3,95 & 5,20 & 6,71 & 6,26 \\
\hline $\mathrm{FeO}$ & 37,48 & 0,18 & 37,56 & 34,50 & 41,76 & 38,80 & 41,90 & 41,53 & 37,19 & 39,80 & 40,00 \\
\hline $\mathrm{MnO}$ & 4,61 & 0,04 & 5,12 & 3,51 & 2,79 & 5,53 & 3,37 & 2,85 & 6,08 & 3,45 & 3,27 \\
\hline $\mathrm{MgO}$ & 0,04 & n.d. & n.d. & 0,07 & 0,03 & 0,02 & n.d. & 0,04 & 0,03 & 0,01 & n.d. \\
\hline $\mathrm{CaO}$ & n.d. & 0,08 & 0,04 & 3,90 & 0,05 & 0,31 & 0,01 & 0,03 & 0,01 & 0,01 & 0,02 \\
\hline Total & 98,70 & 100,88 & 98,41 & 100,29 & 100,29 & 99,69 & 99,82 & 98,00 & 96,82 & 98,20 & 97,77 \\
\hline \multicolumn{12}{|c|}{ Membros finais (\% mol.) } \\
\hline Hem & 17,07 & 99,16 & 14,53 & 17,63 & 10,73 & 9,38 & 7,54 & 7,37 & 9,68 & 12,21 & 11,48 \\
\hline $\mathrm{Ilm}$ & 73,63 & 0,13 & 74,83 & 65,56 & 83,29 & 78,54 & 85,55 & 86,22 & 77,30 & 80,59 & 81,76 \\
\hline Pirof & 9,15 & 0,06 & 10,34 & 6,81 & 5,67 & 11,29 & 6,90 & 5,93 & 12,86 & 7,04 & 6,76 \\
\hline
\end{tabular}

Notas: * - salienta grão de martita; IC - inclusão composta; demais observações como na tabela 4. 


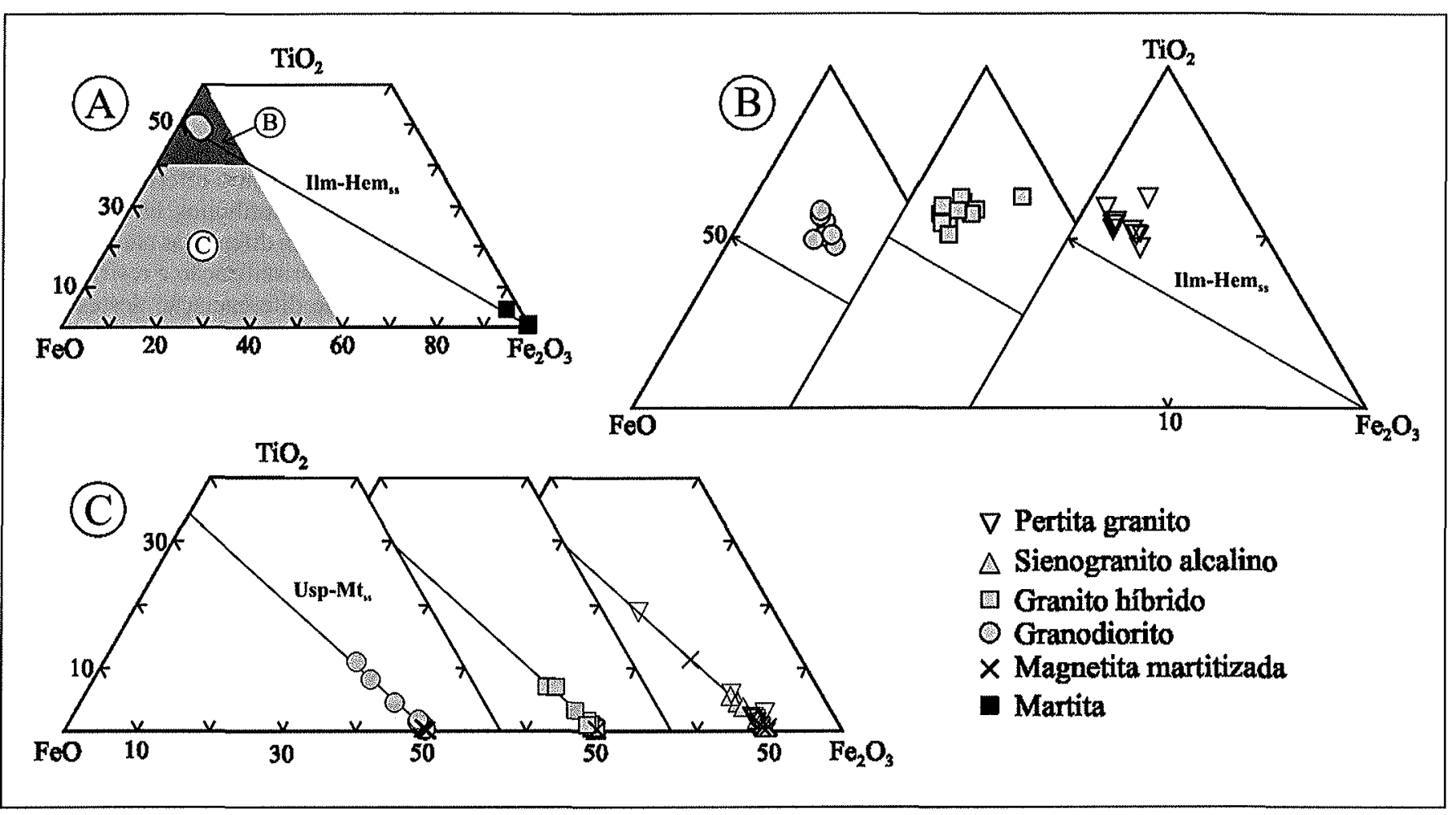

Figura 10 - Diagramas ternários TiO2-FeO-Fe2O3 (\% mol.) para Mt-Uspss e Ilm-Hemss dos granitos do complexo intrusivo Lavras do Sul, com as subdivisões segundo Haggerty (1976). A-Seção basal do diagrama exibindo a composição de ilmenita dos três conjuntos de granitos, discriminados em B. C-Detalhe do campo Mt-Uspss com a discriminação de Ti-magnetita dos três conjuntos de granitos. Martita corresponde a porções de magnetita transformadas para hematita, normalmente situada na borda dos grãos, e magnetita martitizada àquelas porções centrais de grãos parcialmente transformados.

3). As razões $\mathrm{Fe} / \mathrm{Mg}$ de biotita e anfibólio sugerem variações na condição redox durante a cristalização, enquanto composição e microtexturas dos óxidos de Fe-Ti indicam a importância da oxidação subsolidus. Estes processos foram mais intensos nos granodioritos centrais, cuja cristalização teria iniciado em condições mais redutoras a julgar pela maior abundância de Ilm precoce (Tabs. 1 e 3). Isto pode ser atribuído à saturação e exsolução de fluidos aquosos, como registram as texturas. Assim, os processos de descompressão e desvolatilização seriam responsáveis por condições mais oxidantes, e justificariam também o decréscimo nos percentuais de anfibólio (Tab. 1, Fig. 3B). O $\mathrm{ABM}$ representaria um pulso anterior, cristalizado a maior pressão e em condições de subsaturação em $\mathrm{H}_{2} \mathrm{O}$. A maior razão Ti$\mathrm{Mt}: I l m$ no ABM sugere cristalização em condições mais oxidantes que o $\mathrm{BG}$, o que pode ser devido ao efeito da pressão ou ao controle da fase fluida magmática.

A natureza particular do sienogranito híbrido é evidenciada pelo contraste na afinidade, como definida pela geoquímica da rocha e silicatos máficos (Gastal \& Lafon 2006). A mudança na composição do líquido residual é sugerida pela composição da biotita e titanita, A cristalização do ABS relativo ao $\mathrm{ABM}$ teria ocorrido em níveis mais rasos (2-3 kbars, Tab. 3). Os dois tipos híbridos (ABM-ABS) plotam próximo ao eutético do sistema haplogranítico a 2 kbars, sendo que o ABS possui menor $q$ normativo. Desta forma, é possível especular que o favorecimento do Kfs relativo ao Qtz na cristalização desta fácies se deve a recarga com líquido quartzo traquítico. Este processo teria ocorrido durante ou logo após o soerguimento da intrusão central provocado pelo BG. Dois outros fatores são importantes ao entendimento desta variedade de granito híbrido: (a) escassez de feições de dissolução típicas do processo de interação ocorrido na porção central; e (b) associação com stocks de granitos alca- linos distribuídos ao longo da borda E-NE do corpo (Fig. 1B) Estas características são consistentes com a idéia de que o ABS representa líquido fracionado do $\mathrm{ABM}$ que foi contaminado pelo magma granítico alcalino, como sugeriu Nardi (1984). Os contrastes na afinidade seriam um indicativo de que este processo de interação ocorreu no estágio tardi-magmático.

GRANITOS ALCALINOS No BAS e PG, o fracionamento mineral foi mais significativo, como indicado pela química da rocha, anfibólios e biotita (Figs 3-5, Tab. 3). Diferenças na ordem de cristalização podem ser atribuídas a fatores distintos como fracionamento e recarga com líquido básico. Nos termos menos evoluídos (BAS e PG seriado), os processos de mistura de magmas básico e granítico foram importantes, sendo responsáveis por pequenas variações nas condições de oxi-redução. Porém, isto parece ter ocorrido em momentos distintos da cristalização de cada um. Texturas e mineralogia no PG seriado indicam que tal processo ocorreu no início da cristalização, resultando em modificações mais intensas na composição e razão $\mathrm{H}_{2} \mathrm{O} /(\mathrm{F}+\mathrm{Cl})$. Isto teria favorecido a cristalização do $\mathrm{Pl}$ e inibido a formação de agregados de Qtz e Kfs, típicos do PG equigranular. No BAS, os processos de mistura teriam ocorrido durante a formação do arcabouço da rocha, resultando na bimodalidade da granulação e preservação de desequilíbrios texturais. Para estes granitos, a estimativa da pressão com base no $\mathrm{Al}_{\text {, do an- }}$ fibólio ( $\mathrm{Fe}^{*}>0,72$ e baixo $\mathrm{Al}$ ) é problemática, como discutido por Anderson \& Smith (1995). Contudo, Gastal (2004) estimou pressões de 2-3 kbars no BAS, e níveis mais rasos para o $\mathrm{PG}$. $\mathrm{O}$ decréscimo no conteúdo de biotita e crescimento de $\mathrm{Mt}$, neste último, é consistente com o controle da mineralogia nas condições redox e cristalização a pressão sucessivamente menor $(\sim 1$ kbar). É possível sugerir que estes granitos derivaram de magma 


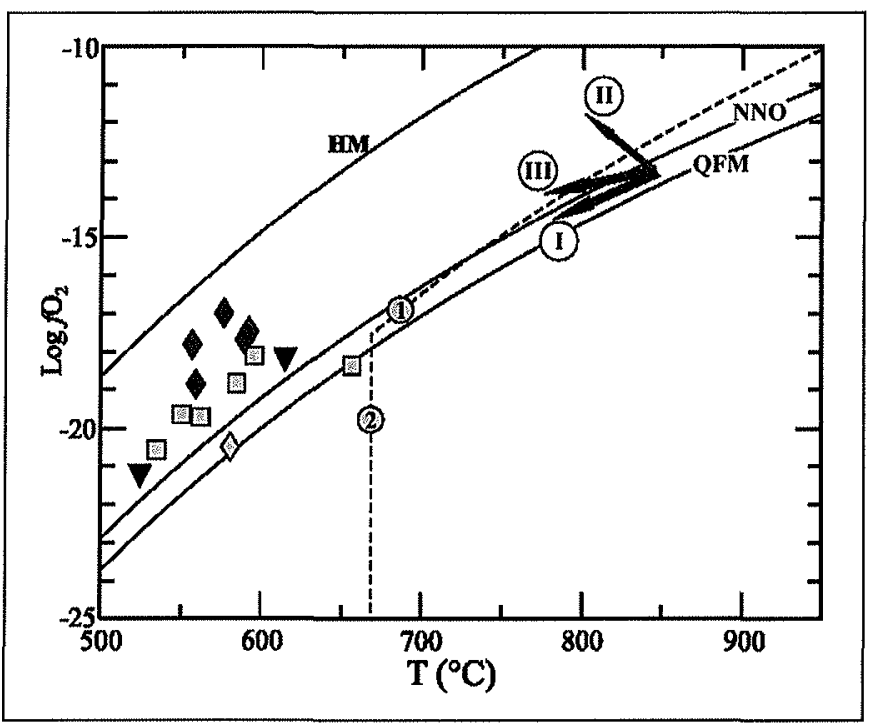

Figura 11 - Diagrama T-log $\mathrm{fO}_{2}$ esquematizando a trajetória redox durante a cristalização de rochas intrusivas, fundamentadas no estudo de biotita (Speer 1984): I - trend normal controlado pelo equilibrio mineral; II - trend fortemente oxidante resultante da vesiculação ou introdução de $\mathrm{O}_{2}$ atmosférico; e III - trend de magmas hidratados quando a capacidade tampão da $\mathrm{H}_{2} \mathrm{O}$ supera a dos minerais (Mueller 1971), ou devido ao efeito de $\mathrm{SO}_{2}$ na fase fluida (Takagi \& Tsukimura 1997). Associações oxy-buffers, segundo Frost (1991), para 2 kbar (linha cheia): QFM-quartzo-faialita-magnetita, NNO-Ni-NiO; e HM-hematita-magnetita; e linha tracejada para estabilidade da titanita (Wones 1989), sendo 1 - hedenbergita-ilmenita-titanita-magnetita-quartzo, e 2-hedenbergita-ilmenita-titanita-faialita. São mostrados os pares de Ti-magnetita-ilmenita em equilibrio nos granitos do CILS, os quais registram as condições subsolidus; $\mathrm{T}_{\text {e }} \mathrm{O}_{2}$ calculadas segundo formulação de Andersen \& Lindsley (1985). Símbolos como na figura 3.

parental intrinsecamente mais oxidado, em face da ausência de Ilm precoce e da presença de titanita primária nos termos menos evoluídos (BAS e PG seriado). A alternativa seria de que tais características se devem apenas à natureza mais alcalina destes granitos (Frost et al. 2001). Porém, a cristalização ocorreu em condições de subsaturação em $\mathrm{H}_{2} \mathrm{O}$ e a partir de magma com menor conteúdo inicial de $\mathrm{H}_{2} \mathrm{O}(<2 \%)$, a julgar pela natureza tardia do anfibólio na cristalização (Tab. 3).

Embora a composição química dos granitos alcalinos seja consistente com a diferenciação de um mesmo magma parental, as idades ${ }^{206} \mathrm{~Pb} /{ }^{238} \mathrm{U}$ e ${ }^{207} \mathrm{~Pb} /{ }^{206} \mathrm{~Pb}$ sugerem que BAS e PG representam mais de um episódio ígneo (Gastal et al. 2006). O BAS, com idade ${ }^{207} \mathrm{~Pb} /{ }^{206} \mathrm{~Pb}$ de $598 \pm 3 \mathrm{Ma}(2 \sigma)$, equivaleria a um pulso alcalino precoce e posicionado ao redor, durante ou logo após a ressurgência central. As idades ${ }^{206} \mathrm{~Pb} / 238 \mathrm{U}(<1 \%$ discórdia) no PG exibem duas populações bem distintas $-599,2 \pm 1,8$ $\mathrm{Ma}(2 \sigma)$ e $586,0 \pm 2,8 \mathrm{Ma}(2 \sigma)$, permitindo indicar que algumas das ocorrências desta fáceis são mais jovens, como propuseram Leite et al. (1998).

TRAJETÓRIA REDOX O estabelecimento da trajetória redox $\left(\mathrm{T}-f \mathrm{O}_{2}\right)$ durante a cristalização dos granitos é dificultado em face do re-equilíbrio subsolidus dos óxidos de Fe-Ti, e das imprecisões na estimativa da razão $\mathrm{Fe}^{+3} / \mathrm{Fe}^{+2}$ de biotita e anfibólios. Apesar disto, é possível fazer algumas inferências com base na comparação dos dados obtidos e aqueles da literatura. Nos granitos do núcleo, inicialmente mais redutores e hidrata- dos, a oxidação durante a cristalização se deve à ação da fase fluida em situações distintas, de equilíbrio cristal-volátil dissolvido (ABM) ou exsolução (BG). Estas situações poderiam corresponder respectivamente aos trends III e II mostrados na figura 11 , enquanto os granitos alcalinos, mais anidros e oxidados, teriam evoluído segundo o trend normal-I. A trajetória redox II corresponde a situações de desvolatilização, em que a dissociação da $\mathrm{H}_{2} \mathrm{O}$ e a perda diferencial de $\mathrm{H}_{2}$ atuam como meio fortemente oxidante. O trend III, segundo Mueller (1971), representa a cristalização de magma hidratado em que a capacidade tampão da $\mathrm{H}_{2} \mathrm{O}$ dissolvida supera a dos minerais máficos. Takagi \& Tsukimura (1997), no entanto, discutem os trends I e III em termos do conteúdo de $\mathrm{SO}_{2}$ na fase fluida magmática que, segundo os autores, é o principal agente oxidante na cristalização. A divergência das trajetótias redox na cristalização dos granitos do CILS teria resultado na reversão das condições no estágio pós-magmático. Isto é aparentemente confirmado pelas estimativas de Te $f \mathrm{O}_{2}$, de pares Mt-Usp e Ilm-Hem em equilíbrio, que registram as condições subsolidus (Fig. 11).

Zoneamento magnético As propriedades magnéticas refletem a partição do $\mathrm{Fe}$ entre os minerais fortemente e os fracamente magnéticos, o que depende da composição química, petrogênese e de condições de oxi-redução. Clark (1997) salienta que a $\mathrm{k}$ de uma rocha com percentuais baixos a moderados de Mt é proporcional ao seu conteúdo, independente da granulação $(>20 \mu \mathrm{m})$ e textura (distribuição). Nos granitos estudados, esta relação é válida, em linhas gerais, em face da grande dispersão em diagrama de correlação de opacos vs. k (Fig. 8A). Nos granitos do núcleo, a maior contribuição de anfibólio e biotita é sugerida pela correlação positiva entre o conteúdo de máficos e k (Fig, 8A). A dispersão observada pode ser, em parte, atribuída ao efeito das transformações subsolidus, que foram mais intensas nos termos do núcleo. A oxi-exsolução acarreta a mudança da composição no sentido dos membros puros das séries $-\mathrm{Mt}_{\mathrm{ss}}$ e $\mathrm{Ilm}_{\mathrm{ss}}$. Para Mt-Usp $\mathrm{ss}_{\mathrm{ss}}$ isto poderia implicar no aumento relativo da $\mathrm{k}$ intrínseca (Carmichael 1996), se as variações no conteúdo de Ti forem significativas (Clark 1997). Efeito contrário pode ser ocasionado pelas substituições, tanto de alta (oxidação pseudomórfica - Haggerty 1991) como de baixa $T$, uma vez que os minerais formados são paramagnéticos ou antiferromagnéticos. A maior intensidade deste processo ocorreu nos granitos dispostos ao longo de zona de falha de direção NE-SW, posicionada diagonalmente no centro do pluton (Fig. 7A). Nesse caso, a formação de martita responde pelos valores mais baixos de $\mathrm{k}\left(<410^{-3} \mathrm{SI}\right)$. No pluton, em geral, os valores crescentes de $\mathrm{k}$ parecem traduzir variações na natureza geoquímica e trajetória redox durante a cristalização dos granitos. E possível concluir que os processos responsáveis por tais variações acompanharam a evolução e posicionamento de fácies, no sentido da diferenciação do núcleo para borda, como sugere a correlação negativa entre o conteúdo de Pl e k (Fig. 8A).

Os granitos do núcleo, $\mathrm{BG}$ e $\mathrm{ABM}$, representam magmas graníticos álcali-cálcicos, hidratados $\left(4-3 \% \mathrm{H}_{2} \mathrm{O}\right)$, onde as variações na trajetória redox podem ser atribuídas ao comportamento diferenciado da fase fluida magmática em pulsos sucessivos posicionados durante o soerguimento do corpo (4 para 3-2 kbars). O estágio subsolidus nestes granitos foi marcado pela circulação mais intensa de fluidos aquosos a $\mathrm{T}$ um pouco abaixo da solidus $\left(600-500^{\circ} \mathrm{C}\right)$. Desta forma, os baixos valores de $\mathrm{k}\left(\sim 4,5-5,510^{-3}\right.$ SI) no BG e ABM traduzem à filiação álcali-cálcica e o efeito menor da oxidação pseudomórfica. A natureza geoquímica particular do granito híbrido evoluído, $\mathrm{ABS}$, pode ser relacionada à interação com o magma granítico alcalino nos estágios finais da cristalização. Assim, os valores intermediários de $\mathrm{k}\left(\sim 7,710^{-3} \mathrm{SI}\right)$, nesta fácies, estariam revelando a área de influência dos granitos 
alcalinos em subsuperficie. BAS e PG representam magmas graníticos alcalinos, mais anidros $\left(<2-1 \% \mathrm{H}_{2} \mathrm{O}\right)$, em que as variações na trajetória redox se devem ao efeito preponderante da descompressão de pulsos sucessivos posicionados em níveis crustais mais rasos (2-1 kbar). Nesses, o estágio subsolidus foi marcado pela circulação de líquidos graníticos residuais a T solidus. Portanto, a afinidade alcalina e o efeito da descompressão justificam os valores mais elevados de $\mathrm{k}\left(9-1010^{-3} \mathrm{SI}\right)$ no PG e BAS.

Em resumo, é possível concluir que o zoneamento magnético, obtido para o pluton granítico do CILS (Fig. 7A), evidencia a ressurgência central construída durante o posicionamento dos granitos álcali-cálcicos e a região de influência dos granitos alcalinos, aflorantes ou em subsuperfície, que foram posicionados durante a ressurgência ao longo da periferia do pluton. O padrão circular das zonas magnéticas sugere também a ampliação da área de ocorrência dos granitos alcalinos em profundidade (Figs. 1A e 7A).

Zonalidade reversa e ressurgência. $O$ corpo principal do CILS é uma intrusão multicíclica, cuja formação resultou na zonalidade reversa de fácies petrográficas (Fig. 1B), também revelada pelo zoneamento magnético (Fig. 7A). A concordância entre o padrão de zonas magnéticas e os dados residuais aeromagnéticos e gravimétricos, detalhados em Gastal et al. (2006, Fig. 4) e Ferreira et al. (em preparação), sugere mecanismos de posicionamento distintos para os dois grupos de granitos (núcleo e alcalinos). Com base no conjunto de informações, podem ser visualizados dois grandes episódios na construção do pluton granítico, quais sejam:

(1) Formação da intrusão central com sucessivos pulsos de magma granítico álcali-cálcico, mais hidratado e de menor temperatura, acompanhando um dos eventos de grande soerguimento (4 para 3-2 kbars), durante o principal período de construção do CILS ( $\sim 603-597 \mathrm{Ma})$. Isto resultou na zonalidade reversa, com BG no centro e granitos híbridos ao redor, os últimos poderiam representar margens resfriadas ou um pulso anterior. $\mathrm{O}$ núcleo granodiorítico coincide com as principais raízes alimentadoras do pluton, controladas por estruturas pré-existentes (Gastal et al. 2006). Isto permite interpretar o BG como uma intrusão formada durante a ressurgência no centro da câmara magmática, o que é comum após um período de subsidência de caldeiras (Johnson et al. 2002), e que pode ou não estar associada à formação de condutos centrais (Saunders 2005). Bolsões de $\mathrm{BG}$ porfirítico e diques de dacito/riolito, localizados na porção central, podem estar indicando as zonas de dilatação esperadas neste tipo de estrutura dômica (Withjack \& Scheiner 1982).

(2) Formação de intrusões anelares com diferentes pulsos de magma granítico alcalino, mais anidro e de $\mathrm{T}$ elevada, dispostos ao redor da intrusão central e também associadas ao soerguimento da câmara magmática. Este evento teria iniciado logo após a ressurgência central, com a formação do BAS ( $598 \mathrm{Ma})$ e, assim, teria promovido a contaminação dos granitos híbridos na periferia do corpo central. O término deste evento pode ter se prolongado até 586-580 Ma, que é a idade do PG e de granitos hidrotermalizados. As intrusões anelares também exibem zonalidade reversa, com os termos menos evoluídos dispostos no interior das ocorrências e relacionados à recarga com magma básico, o que é referendado por importante alinhamento magnético (Gastal et al. 2006).
O extremo efeito do fracionamento mineral entre os granitos alcalinos, relacionados a pulsos distintos, é consistente com a idéia de que a ressurgência ao longo da periferia do pluton foi um processo prolongado. Isto justificaria, em parte, o intervalo das idades isotópicas ( $\sim 598-586 \mathrm{Ma})$, bem como o aquecimento prolongado do pluton e, assim, a pouca definição nas relações de intrusão entre pulsos distintos. Todas estas feições são consistentes com o modelo de formação de diques anelares durante a ressurgência ao longo de falhas circulares (circumferential faults), geradas ou não em eventos prévios de subsidência (Saunders 2005). Este tipo de ressurgência, segundo Saunders (2005), marca o final de eventos ígneos em sistemas de subsidência formados durante regime tectônico extensional.

CONCLUSÕES. Os resultados obtidos realçam a importância dos estudos de petrologia magnética em plutons mineralizados, como é o caso dos granitos do CILS. O estudo integrado da química de silicatos máficos e de óxidos de Fe-Ti foram relevantes para o entendimento das condições de oxi-redução, como referido em estudos prévios (Czamanske et al. 1981). Apesar da facilidade de re-equilíbrio subsolidus, microtexturas e composição dos minerais óxidos de Fe-Ti forneceram informações complementares às obtidas com o estudo de biotita e anfibólios. $\mathrm{O}$ entendimento do ambiente termodinâmico permitiu a melhor distinção dos dois conjuntos de granitos do CILS, em termos petrológicos e metalogenéticos. Embora os termos alcalinos com maior suscetibilidade magnética-k tenham cristalizado em condições de $\mathrm{fO}_{2}$ mais elevada, as maiores variações nas condições de $\mathrm{O}_{2}$ ocorreram nos granitos do núcleo, que exibem baixa $\mathrm{k}$. Estes derivaram de magma parental hidratado e intrinsecamente mais redutor. Deste modo, estes seriam os granitos potencialmente vinculados à gênese das mineralizações segundo critérios de Takagi \& Tsukimura (1997).

As principais ocorrências de $\mathrm{Au}-\mathrm{Cu}$, na porção central do pluton (Fig. 1B), estão dispostas ao longo das regiões de dilatação, possivelmente relacionada ao evento de ressurgência central. No entanto, as mineralizações de maior possança estão alojadas nos granitos alcalinos (Reischel 1980, Mexias 2000), o que poderia ser atribuído a reconcentração do minério durante os eventos ígneos finais de maior temperatura, como referido por Nardi \& Lima (1988). Os dois processos de ressurgência são consistentes com a localização das mineralizações em zonas de interação de pulsos graníticos, permitindo estabelecer o vínculo entre a origem destas e a evolução do pluton, como visualizado em exemplos clássicos de depósitos do tipo pórfiro (Phillips 1973, Tiltey \& Beane 1981). Para o perfeito entendimento destas questões são necessários o melhor conhecimento dos mecanismos de colocação dos granitos, fundamentado na gravimetria e anisotropia de suscetibilidade magnética, e o levantamento detalhado das estruturas tectônicas frágeis na região do complexo intrusivo.

Agradecimentos Este trabalho foi financiado com auxilios oriundos da FAPERGS n ${ }^{\circ}$ 98/0662.1, 00/2366.3 e 02/0611.7, e PRONEX/CPGq - IGEO-UFRGS. Somos gratos a CPRM - Serviço Geológico do Brasil, que nos forneceu os dados aeromagnetométricos da região e o Kappameter KT-3. Agradecemos a colaboração de revisores anônimos, bem como a assistência conferida pelo staff dos laboratórios de Microssonda Eletrônica/CPGqUFRGS e do Centro de Microscopia Eletrônica/CME-UFRGS. 


\section{Referências}

Andersen, D.J. \& Lindsley, D.H. 1985. New (and final!) models for the Ti-magnetite/ilmenite geothermometer and oxygen barometer. AGU Spring Meeting Eos Transc., Am. Geophys. Union, 66(18): 416.

Anderson, J.L. \& Smith, D.R. 1995. The effects of temperature and $f \mathrm{O}_{2}$ on the Al-in-hornblende barometer. Am. Mineral, $80(5 / 6): 549$. 559 .

Borradaile, G.J. \& Henry, B. 1997. Tectonic applications of magnetic susceptibility and its anisotropy. Earth Sci. Rev., 42:49-93.

Bouchez, J.L. 2000. Anisotropie de susceptibilité magnétique et fabrique des granites. C.R. Acad. Sci. Paris, 330:1-14.

Carmichael, R.S. 1996. Handbook of Physical Properties of Rocks. CRC Press, v. 2., 345p.

Clark, D.A. 1997. Magnetic petrophysics and magnetic petrology: aids to geological interpretation of magnetic surveys. AGSO J. Austr. Geol. Geophys., 17(2):83-103.

Czamanske, G.K., Ishihara, S, Atkin, S.A. 1981. Chemistry of rockforming minerals of the Cretaceous-Paleocene batholith in southwestern Japan and implications for magma genesis. J. Geophys. Res., 86-B11:10431-10469.

Eby, G. N., 1990. The A-type granitoids: A review of their occurrence and chemical characteristics and speculations on their petrogenesis. Lithos, 26(1/2):115-134.

Frost, B.R. 1991. Introduction to oxygen fugacity and its petrologic importance. In:Lindsley, D.H. (Ed.). Oxide Minerals: Petrologic and Magnetic Significance. Rev. Mineral., 25:1-9.

Frost, B.R. \& Lindsley, D.H. 1991. Occurrence of Iron-titanium oxides in igneous rocks. In: Lindsley, D.H. (Ed.). Oxide Minerals: Petrologic and Magnetic Significance. Rev. Mineral., 25:433-468.

Frost, B.R., Barnes, C.G., Collins, W.J., Arculus, R.J., Ellis, D.J., Frost, C.D. 2001. A geochemical classification for granitic rocks. J. Petrol., 42(11):2033-2048.

Gastal, M.C.P. 1998. Suite Intrusiva Saibro, RS: Avaliação de um Modelo Petrológico. Tese de Doutoramento em Geociências, Instituto de Geociências, Universidade Federal do Rio Grande do Sul, 365 p.

Gastal, M.C.P. 2004. Química mineral de granitóides e minetes do Complexo Intrusivo Lavras do Sul, comparada à de rochas vulcânicas cronocorrelatas. In: CPGq/UFRGS, Encontro Dez anos de microssonda eletrônica em Porto Alegre, 1, Resumos expandidos, p. 67-78.

Gastal, M. C. P. \& Lafon, J. M. 1998. Gênese e evolução dos granitóides metaluminosos de afinidade alcalina da porção oeste do Escudo Sul-riograndense: geoquímica e isótopos de $\mathrm{Rb}-\mathrm{Sr}$ e $\mathrm{Pb}-\mathrm{Pb}$. Rev. Bras. Geoc. 28(1), 11-28.

Gastal, M. C. P. \& Lafon, J. M. 2006. Reinterpretação do Complexo Intrusivo Lavras do Sul, RS, de acordo com os sistemas vulcanoplutônicos de subsidência. Parte 2: química mineral, geoquímica e isótopos de Pb-Sr-Nd. Rev. Bras. Geoc., 36(1): 121-142.

Gastal, M. C. P., Lafon, J.M., Ferreira, F.J.F., Magro, F.U. S., Remus, M.V.D., Sommer, C.A. 2006. Reinterpretação do Complexo Intru- sivo Lavras do Sul - RS, de acordo com os sistemas vulcano-plutônicos de subsidência. Parte I: Geologia, geofísica e geocronologia $\left({ }^{207} \mathrm{~Pb} /{ }^{206} \mathrm{~Pb} \mathrm{e}^{206} \mathrm{~Pb} /{ }^{238} \mathrm{U}\right)$. Rev. Bras. Geoc., 36(1): 106-120.

Haggerty, S.E. 1991. Oxide Textures - A Mini-Atlas. In: Lindsley, D.H. (Ed.). Oxide Minerals: Petrologic and Magnetic Significance. Rev. Mineral., 25:129-219.

Ishihara, S. 1981. The granitoid series and mineralization. Econ. Geol., 75: $458-484$.

Jackson, V.N., Ramos, V.A, Terry, S.A, Zuzek, A B. 1973. Projeto Aerogeofisico Camaquã, Estado do Rio Grande do Sul. Porto Alegre, Texas Instruments, DNPM/CPRM/CENEN, 208p.(inédito).

Johnson, S.E., Schmidt, K.L., Tate, M.C. 2002. Ring complexes in the Peninsular Ranges Batholith, Mexico and the USA: magma plumbing systems in the middle and upper crust. Lithos, 61:187-208.

Le Maitre, R.W. (Ed.). 1989. A Classification of Igneous rocks and Glossary of terms: recommendations of the International Union of Geological Sciences Subcommission on the Systematics of Igneous Rocks.Oxford, Blackwell Scientific Publications, 193p.

Leite, J.A.D., Hartmann, L.A., McNaughton, N.J., Chemale Jr. 1998. SHRIMP U/Pb zircon geochronology of Neoproterozoic juvenile and crustal-reworked terranes in southernmost Brazil. Intern. Geol. Rev., 40:683-705.

Lima, E.F. de 1995. Petrologia das rochas vulcânicas e hipoabissais da Associação Shoshonítica de Lavras do Sul, RS. Tese de Doutoramento em Geociências, Instituto de Geociências, Universidade Federal do Rio Grande do Sul, 338p.

Matos Neto, J.B., De Ros, L.F., Ferrari, M. 1980. Projeto Folha Lavras do Sul-RS. Geologia da faixa I. Trabalho de Graduação, Instituto de Geociências, DNPM-UFRGS, 349p.

Mexias, A.S. 2000. Alteração hidrotermal associada ao Distrito Aurífero de Lavras do Sul, RS-A área do Bloco Butiá. Tese de Doutoramento, Instituto de Geociências, Universidade Federal do Rio Grande do Sul, 360p.

Mueller, R.F. 1971. Oxidative capacity of magmatic components. Amer. J. Sci., 278:715-724.

Nardi, L. V. S. 1984. Geochemistry and Petrology of the Lavras Granite Complex, RS, Brazil. Doctor of Philosophy Thesis, Department of Geology King's College, University of London, 268p.

Nardi, L.V.S. \& Lima, E.F. de 1988. Hidrotermalismo no Complexo Granítico Lavras e vulcânicas associadas, RS. Rev. Bras.

Geoc., 18(3): 369-375.

Nardi, L.V.S. \& Lima, E.F. de 2000. Hybridisation of mafic microgranular enclaves in the Lavras Granite Complex, southern Brazil. $J$. South Amer. Earth Sci., 13:67-78.

Nekvasil, H. 1990. Reaction relations in the granite system: Implications for trachytic and syenitic magmas. Am. Mineral.,75(5/6); 560-571.

Phillips, W.J. 1973. Mechanical effects of retrograde boiling and its probable importance in the formation of some porphyry ore deposits. Trans. Instn. Min. Metall. (see B: Appl. Earth Sci.), 95: B90B98. 
Reischel, J.L. 1980. Mineralizações auriferas associadas ao Complexo Granítico de Lavras do Sul, RS. In: SBG, Cong. Bras. Geol., 31, Anais, p. 1700-1712.

Salonsaari, P.T. 1995. Hybridization in the subvolcanic Jaala-litti Complex and its petrogenetic relation to rapakivi granites and associated mafic rocks of southeastern Finland. Bull. Geol. Soc. Finland, 67: 1-104.

Saunders, S.J. 2005. The possible contribution of circumferential fault intrusion to caldera resurgence. Bull. Volcanol., 67:57-71.

Speer, J.A. 1984. Micas in igneous rocks. In: Bailey, S.W. (Ed.) Micas. Rev. Mineral., 13:299-356.

Takagi, T. \& Tsukimura, K. 1997. Genesis of oxidized- and reducedtype granites. Econ. Geol., 92:81-86.

Titley, S. R. \& Beane, R. E. 1981. Porphyry copper deposits. Econ. Geol, 75 $^{\text {th }}$ Anniv. Vol., 214-269.
Vernon, R.H. 1990. Crystallization and hybridism in microgranitoid enclave magmas: microstructural evidence. J. Geophys. Res., 95: $17849-17859$.

Vieira Jr., N. \& Soliani Jr., E. 1989. Um novo modelo genético-evolutivo para o Maciço Granítico de Lavras do Sul, RS. Acta Geol. Leop., 29(12): 143-160.

Withjack, M. O. \& Scheiner, C. 1982. Fault patterns associated with domes - An experimental and analytical study. Amer. Assoc. Petrol. Geol. Bull., 66(3):302-316.

Wones, D.R. 1989. Significance of the assemblage titanite + magnetite + quartz in granitic rocks. Am. Mineral., 74(7/8):744-749.

Wones, D.R. \& Eugster, H.P. 1965. Stability of biotite - experiments, theory and application. Am. Mineral, 50(9):1288-1292.

Manuscrito A-1505 Revisão aceita em 14 de junho de 2006 